\title{
Transparência no setor público: uma análise dos relatórios de gestão anuais de entidades públicas federais no ano de 2010
}

\author{
Maria Amália da Costa Bairral \\ Controladoria Geral da União / Controladoria \\ Brasília / DF - Brasil \\ Adolfo Henrique Coutinho e Silva \\ Universidade Federal do Rio de Janeiro (UFRJ) / Faculdade de Administração e Ciências \\ Contábeis (Facc) / Departamento de Ciências Contábeis \\ Rio de Janeiro / RJ - Brasil
}

Francisco José dos Santos Alves

Universidade do Estado do Rio de Janeiro (Uerj) / Departamento de Ciências Contábeis (FAF)

/ Programa de Pós-Graduação em Ciências Contábeis

Rio de Janeiro / RJ - Brasil

\begin{abstract}
O presente estudo analisa o nível de transparência pública nos relatórios de gestão anuais de entidades públicas federais e os incentivos (político, institucional, governamental, social e financeiro) que podem afetar a divulgação da informação pública. Aborda-se a perspectiva da teoria de agência e da prestação de contas (public accountability) na divulgação da informação, pois os gestores governamentais podem disponibilizar ao cidadão uma informação incompleta (conflito de agência). Nesse sentido, uma maior transparência da informação pública pode servir como uma forma de aproximação entre o principal (cidadão) e o agente (gestor público). Realizou-se uma pesquisa empírica, de natureza quantitativa, para análise do nível de transparência apresentado nos Relatórios de Gestão de 2010 de 115 entidades públicas federais. Para tanto, foi construído um Índice de Transparência Pública Federal (ITPF), baseado em estudos internacionais, de modo a verificar o nível de divulgação da informação pública apresentado nos relatórios de gestão anuais e os incentivos que afetam essa divulgação. Os resultados apontam um baixo nível de transparência pública nos relatórios de gestão (48\%), deficiências na divulgação obrigatória (80\%) e baixa aderência às práticas de evidenciação voluntária (19\%). Sobre os incentivos para a divulgação, se observou uma relação positiva entre o tipo de entidade, acessibilidade e demografia de pessoal com o índice de transparência pública, enquanto a burocracia pública mostrou uma relação negativa. Já o porte, tamanho do núcleo de gestão, receita orçamentária e dependência federal não influenciam a divulgação da informação pública nos relatórios de gestão.
\end{abstract}

Palavras-chave: transparência pública; relatórios de gestão; incentivos governamentais.

DOI: http://dx.doi.org/10.1590/0034-7612125158

Artigo recebido em 16 out. 2013 e aceito em 17 dez. 2014.

(cc) BY-NC

Rev. Adm. Pública - Rio de Janeiro 49(3):643-675, maio/jun. 2015 
Transparencia en el sector público: un análisis del nivel de transparencia de los reportes anuales de las entidades públicas federales en el año de $\mathbf{2 0 1 0}$

El estudio analiza el nivel de transparencia pública en los informes de gestión anual de las entidades públicas federales y los incentivos (político, institucional, gubernamental, social y financiero) que pueden afectar a la difusión de la información pública. Se acercó la perspectiva de la teoría de la agencia y la necesidad de la rendición de cuentas (public accountability) en la difusión de la información pública, porque los administradores del gobierno pueden proporcionar información incompleta (conflicto de agencia) a los ciudadanos. Por tanto una mayor transparencia de la información pública puede servir como una forma de acercamiento entre el principal (ciudadanos) y el agente (administrador público). La investigación es empírica, de naturaleza cuantitativa, para el análisis del nivel de transparencia presentado en los informes de gestión anuales de 2010 de 115 entidades públicas federales. Por lo tanto, se construyó un índice de transparencia pública federal (ITPF), basado en estudios internacionales, para comprobar el nivel de divulgación de la información pública presentado en los informes anuales y los incentivos que afectan a la divulgación. Los resultados indican un moderado nivel de transparencia pública (48\%), deficiencias en la divulgación obligatoria mínima (80\%) y baja adherencia a las prácticas de divulgación voluntaria (19\%). Sobre los incentivos para divulgación, se observó una relación positiva con el tipo de entidad, la accesibilidad, la demografía de personal y el índice de transparencia pública, mientras la burocracia pública mostró una relación significativa, pero negativa. Sin embargo, el tamaño, el tamaño de la administración central, los ingresos presupuestarios y la dependencia federal no influyen la divulgación de la información pública in los informes anuales.

Palabras clave: transparencia pública; informes de gestión anuales; incentivos del gobierno.

Disclosure in public sector: an analysis of the level of disclosure in the annual reports of Brazilian federal government bodies in the year $\mathbf{2 0 1 0}$

The present study analyzes the level of public transparency in the annual reports of federal public bodies and the incentives (political, institutional, governmental, social and financial) which can affect the disclosure of public information. It approached the Agency Theory and the need for public accountability in the disclosure of information, since government managers may provide incomplete information (agency conflict). Accordingly a greater transparency of public information may serve as a way of approaching the principal (citizens) and the agent (public officer). We carried out an empirical research, quantitative, which analyze the level of transparency presented in the 2010's annual reports of 115 federal public entities. For this purpose, an index of federal public transparency was constructed, based on international studies, in order to verify the level of disclosure presented on the annual reports and the incentives that affect disclosure. The results indicate a moderate level of public transparency (48\%), deficiency of compliance with mandatory disclosure (80\%) and low adherence to voluntary disclosure practices (19\%). Regarding incentives to disclosure, a positive relationship of the entity type, accessibility and personnel demographic with the public transparency index was observed, while public bureaucracy showed a significant relationship, but negative. Meanwhile the size, size of core management, budgetary revenues and federal dependency does not influence the disclosure of public information in the annual reports.

KeYWORDs: public transparency index; annual reports; governmental incentives. 


\section{Introdução}

O tema da transparência da informação pública ganhou maior relevância, no Brasil, a partir da Lei Complementar no 101/2000 (Lei de Responsabilidade Fiscal — transparência na gestão fiscal) e, desde então, normativos legais como a Lei Complementar oㅡ 131/2009 — Lei da Transparência (disponibilização, em tempo real, de informações públicas como: receita, despesa, salário dos servidores públicos, convênios e outros, nos portais eletrônicos nas várias esferas governamentais) e a Lei de Acesso a Informação (LAI) no 12.527/2011 (regulamenta o direito do cidadão à informação pública) iniciaram um ciclo de mudanças na relação cidadão/gestor público. Pois determinaram a divulgação (ativa ou via solicitação), e não o sigilo, como norma geral para a informação pública, envolvendo o fornecimento de dados em uma linguagem acessível e sem barreiras técnicas.

A transparência pública começa a se expandir para além da linha legal/fiscal e passa a abordar outros aspectos da gestão pública (desempenho, pessoal, controles internos etc.). Essa ampliação traz novos requisitos para a responsabilização pública (public accountability), via órgãos de controle, que passam a avaliar se, efetivamente, as informações públicas estão acessíveis ao cidadão seja via relatórios fiscais, portais eletrônicos de transparência e relatórios de gestão anuais.

A transparência é um elemento da comunicação entre cidadão e gestor público, um contrato social tácito em que, na perspectiva da clássica teoria da agência, o principal (cidadão) delega ao agente (gestor público) uma atividade de seu interesse e monitora sua realização. Entretanto, conflitos surgem nessa relação resultando numa informação incompleta (assimetria informacional) em razão da existência de três premissas:

1) O agente (gestor público) dispõe de vários comportamentos possíveis de serem adotados;

2) A ação do agente afeta o bem-estar de ambas as partes;

3) As ações do agente dificilmente são observáveis pelo principal (cidadão), que leva à existência de assimetria informacional. (Slomski, 2007:133).

Tais premissas explicitam a necessidade de avaliar se o agente (gestor público) sempre tomará as decisões que maximizem os interesses do principal (cidadão). Nesse sentido, com vistas a mediar o problema da assimetria informacional, Albuquerque e colaboradores (2007) citam a public accountability (responsabilização pública), a transparência e a tempestividade da informação como uma forma de aproximação entre principal e agente.

Logo, o processo de transparência no setor público, principalmente, no novo cenário de universalização de padrões e conceitos contábeis exigidos pelas International Public Sector Accounting Standards (Ipsas), ${ }^{1}$ torna-se cada vez mais pertinente, pois a divulgação da infor-

\footnotetext{
${ }^{1}$ Elaboradas a partir das International Financial Reporting Standards (IFRS) observadas as características do setor público, as International Public Sector Accounting Standards (Ipsas) dispõem sobre uma contabilidade patrimonial
} 
mação pública, compatível com as boas práticas de evidenciação, seja via relatórios de gestão anuais, fiscais ou portais eletrônicos, proporciona um valioso feedback tanto para os órgãos de controle como para o cidadão (controle social). Os primeiros com o objetivo de fiscalizar o desempenho da gestão pública (public accountability), em consonância com os princípios constitucionais vigentes, e o segundo para avaliar se os atos públicos estão sendo praticados com eficiência e se correspondem aos anseios do cidadão (responsividade) a fim de fazer valer os termos do "contrato social".

Ademais, essa harmonia relacional deve ultrapassar a barreira de pagar tributos (fiscal) e aguardar os resultados, pois a participação da sociedade no regime democrático visa combater as premissas descritas por Slomski e colaboradores (2009), pois, quanto maior o envolvimento da sociedade nos atos de governança pública, mais se espera uma gestão focada na eficiência, eficácia e efetividade da utilização dos recursos públicos. E somente de posse dessas informações os cidadãos poderão escolher melhor seus representantes.

No ambiente acadêmico nacional, apesar de o tema suscitar grande interesse entre os pesquisadores, ainda pouco se sabe sobre o nível de divulgação das informações públicas e sobre os incentivos que afetam essa divulgação. Assim, estudos científicos sobre o tema se configuram numa oportunidade singular de contribuição para a realidade do setor público.

A literatura nacional se concentra nos entes federativos municipais e nos modelos de transparência púbica a partir de web sites e relatórios fiscais (Sacramento e Pinho, 2007; Santana Junior, 2008; Paiva e Zuccolotto, 2009; Cruz, 2010).

Diversamente, a literatura internacional, bastante ampla, sobre transparência no setor público aborda:

(1) diferentes entidades governamentais: (a) federais (Bakar e Saleh, 2011; Herawaty e Hoque, 2007), (b) estaduais (Ingram, 1984; Cheng, 1992), (c) municipais (Gandia e Archidona, 2008; Martani e Lestiani, 2012) e (d) regionais (Zimmerman, 1977; Giroux, 1989);

(2) variados instrumentos de evidenciação: (a) web sites (Laswad, Fisher e Oleyere, 2005; Maingot e Zeghal, 2008), (b) relatórios anuais (Steccolini, 2002; Wei, Davey e Coy, 2008; Bakar e Saleh, 2011) e (c) demonstrativos financeiros (Copley, 1991; Smith, 2004); e

(3) diversos incentivos: (a) político (Zimmerman, 1977), (b) institucional (Giroux, 1989; Bakar e Saleh, 2011), (c) governamental (Ingram, 1984), (d) financeiro e/ou econômico (Smith, 2004; Bakar e Saleh, 2011) e (e) social (Cheng, 1992; Bakar e Saleh, 2011), associados à transparência no setor público.

Considerando a importância de pesquisas sobre índices de transparência pública, o estudo busca analisar os níveis de transparência apresentados nos relatórios de gestão anuais de $2010^{2}$ de 115 entidades públicas federais, do Poder Executivo, e os incentivos

\footnotetext{
integral (registro dos bens, direitos, obrigações e patrimônio líquido) e regime de competência para o reconhecimento das despesas e receitas. A adoção das NBCASP no cenário público brasileiro é gradual, e somente em 2014 todos os entes federativos estarão obrigados à adoção integral.

${ }^{2}$ Os relatórios de gestão analisados se referem a um único período, 2010, divulgados no site "contas públicas" do Tribunal de Contas da União (TCU), pois à época da realização do estudo (2012) representava o ano mais recente disponível.
} 
(políticos, sociais, institucionais, financeiros e governamentais) que podem afetar ou não a divulgação. Para tanto, se construiu um índice de transparência pública federal, a partir da legislação e de estudos internacionais, adaptado ao cenário brasileiro, cuja mensuração com métodos de pontuação dicotômico e ponderado se limitou ao conteúdo dos relatórios de gestão anuais.

A razão que justifica o estudo é a carência de pesquisas empíricas nacionais, que mensurem, a partir de relatórios de gestão anuais, a transparência pública e os incentivos associados à divulgação. O estudo incorpora alguns aprimoramentos, relativos às limitações observadas em estudos internacionais anteriores, quais sejam: (a) identificação, a partir da literatura, de itens de evidenciação qualitativos e quantitativos; (b) segregação dos itens de evidenciação entre voluntário e obrigatório; e (c) utilização de dois métodos de pontuação (simples e ponderado) para mensurar o índice.

O potencial contributivo do estudo reside na ampliação da reflexão crítica sobre evidenciação no setor público, bem como na identificação de incentivos que podem contribuir ou não com a evidenciação.

O texto está distribuído da seguinte forma: além desta seção introdutória, foram estabelecidas quatro seções: a primeira apresenta o referencial teórico do estudo, a segunda exibe o detalhamento dos procedimentos metodológicos, a terceira relata os resultados e análises da pesquisa empírica e, por último, apresentam-se as considerações finais.

\section{Referencial teórico}

\subsection{Teoria da agência, transparência na gestão pública e Public Accountability}

A teoria da agência, de Jensen e Meckling (1976), baseia seus pressupostos numa relação contratual em que o principal encarrega o agente em desenvolver alguma atividade de seu interesse. Entretanto, conflitos surgem nessa relação: (i) divergência de objetivos entre principal e agente, (ii) dificuldade de monitoramento das ações do agente e (iii) divergência de posicionamento, entre principal e agente, em relação ao risco envolvido no gerenciamento dessa atividade (Slomski et al., 2009).

Percebe-se que o problema de agência fundamenta-se principalmente na questão da informação incompleta (assimétrica), que remete à posse, pelo agente (gestor público), de um conjunto privilegiado de informações sobre as atividades desenvolvidas no relacionamento com o principal (cidadão). Assim, com vistas a mediar o problema da assimetria informacional na relação cidadão e gestor público, Albuquerque e colaboradores (2007) citam a accountability, conjuntamente com a transparência, clareza e tempestividade da informação como uma forma de aproximação entre principal e agente.

Também Hendriksen e Van Breda (1999:139) enfatizam o papel pós-decisório na relação de agência: 
Dado que os principais sempre estarão interessados nos resultados gerados por seus agentes, a teoria de agency oferece bases para um papel importante para a contabilidade no fornecimento de informações após a ocorrência de um evento: um chamado papel pós-decisório. Esse papel é frequentemente associado à função de custódia da contabilidade, na qual um agente informa um principal a respeito dos eventos do período passado. É isto que dá a contabilidade seu valor como feedback, além de seu valor preditivo.

Esse papel pós-decisório (valor de feedback), da relação de agência, no setor público é extremamente relevante, na medida em que pode proporcionar melhor transparência das ações governamentais, mas para isso se impõe a necessidade de criação de mecanismos de governança que assegurem uma adequada prestação de contas (public accountability) dos atos públicos por parte dos gestores nos mais diversos níveis governamentais.

Ishikura e colaboradores (2010) mencionam que a accountability não corresponde somente à vontade exclusiva do gestor, mas a uma obrigatoriedade exigida em lei, sob pena de responder por seus atos e sofrer as sanções previstas. Adicionalmente, também existe na accountability um componente político (expectativas e promessas inseridas na relação cidadão/ agente) não restrito às leis.

Nessa linha, o Instituto Brasileiro de Governança Corporativa (IBCG, 2010:19) postula que as organizações que seguem as boas práticas de divulgação devem adotar como princípios básicos: a transparência (obrigação de informar), a equidade (tratamento justo dos stakeholders), a accountability (prestação de contas dos atos e assunção das consequências pelas omissões) e a responsabilidade corporativa (sustentabilidade das entidades). Adicionalmente, postula que os gestores precisam adquirir o desejo de informar, tendo consciência de que a adequada comunicação, interna ou externa, quando voluntária, acessível e célere, proporciona um clima de confiança para os usuários dentro e fora da entidade.

No Brasil, a transparência da gestão pública teve como marco regulatório a promulgação da Lei Complementar no 101/2000 (Lei de Responsabilidade Fiscal — LRF). E, de acordo com Tolentino e colaboradores (2002), essa mudança na transparência da gestão fiscal também passou a demandar maior capacidade de monitoramento do governo federal e do Poder Legislativo (tribunais de contas) para verificar o cumprimento das normas. Na sequência, outras leis como a Lei da Transparência no 131/2009 e, mais recentemente, a Lei de Acesso a Informação Pública — LAI no 12.527/2011 intensificaram a obrigatoriedade na divulgação da informação pública, contribuindo para a responsabilização pública dos gestores.

De acordo com Kim e colaboradores (2005), transparência significa que a informação deve ser completa, de fácil entendimento, acessível, comparável com períodos anteriores, sem viés, e deve, ainda, atentar para os diversos meios em que é possível promover a "ampla divulgação" da gestão pública. Isto é, a responsabilização do gestor pela aplicação dos recursos públicos (escolhas) e pelo dever de prestar contas (informação) sobre o desempenho da gestão perante o usuário (cidadão).

Um bom indicador para essa mudança é a entrada da figura dos usuários (fornecedores, servidores públicos, cidadão, financiadores etc.), cuja definição, no cenário público, seria todo 
aquele que tem um "razoável direito" de conhecer a informação relativa às entidades governamentais, ou seja, inclui todos os grupos ou indivíduos que podem afetar ou são afetados pelas atividades da organização pública (Tooley, Hooks e Basnan, 2010).

Nesse sentido, os relatórios de gestão anuais são um dos mecanismos utilizados pela administração pública para concretizar a responsabilização ${ }^{3}$ dos atos públicos em relação à sociedade. Uma exigência normativa aplicável a todas as entidades (públicas ou privadas) que gerem recursos públicos, e se constituem numa das peças primordiais do processo de prestação de contas estabelecido pelos órgãos de controle (Controladoria Geral da União - CGU e Tribunal de Contas da União - TCU).

A legislação, com periodicidade anual, regulamenta seu conteúdo obrigatório, sua apresentação e divulgação na internet, enquanto seu conteúdo voluntário abrange toda a informação não exigida por lei e que proporciona ao usuário um melhor entendimento da gestão pública. Contudo, a divulgação voluntária não deve conter viés (informação promocional do gestor), mas, conjuntamente com a obrigatória, minimizar o problema da assimetria informacional.

\subsection{Incentivos para divulgar no setor público}

No setor privado existe uma diversidade de estudos empíricos que abordam a questão do nível de evidenciação e testam sua relação com determinantes como: porte, preço de mercado, receita, lucro e outros. Todavia, no setor público se observa um número menor de estudos que abordam os índices sobre o nível de evidenciação e, menos ainda, estudos empíricos sobre incentivos associados à evidenciação.

Conforme Steccolini (2002), as organizações públicas são responsáveis perante a sociedade na disponibilização de informações transparentes e compreensíveis sobre as ações governamentais que desenvolvem. Contudo, os níveis de transparência da informação pública podem variar e essa variabilidade pode estar associada a incentivos que estimulam ou inibem o gestor público a divulgar a informação.

No contexto político, a evidenciação pública é mais comumente associada a variáveis explicativas como a competição política e o porte: a primeira explicita que os gestores estariam dispostos a fornecer mais informação como forma de melhor visibilidade para se elegerem ou permanecerem nos cargos (Perez, Bolivar e Hernandez, 2008) e a segunda, consoante Bakar e Saleh (2011), que entidades maiores possuem maiores custos de agência ${ }^{4}$ e, portanto, divulgam mais informação com vistas a reduzir tais custos.

O incentivo institucional preconiza que as organizações públicas operam dentro um arcabouço político e social e sua sobrevivência dependeria do cumprimento de determinadas

\footnotetext{
${ }^{3}$ Cabe, no entanto, destacar a existência de outras fontes de informação (portais eletrônicos, relatórios fiscais, solicitações do cidadão junto à entidade pública), pois, como sabemos, a transparência pública pode, sim, se dar por diversos meios.

${ }^{4}$ Refletem os custos suportados, pelo principal, para monitorar as ações do agente (Bakar e Saleh, 2011).
} 
regras e procedimentos estabelecidos pela legislação, ou por padrões de práticas de evidenciação adotados pelo setor, como forma de garantir sua legitimidade perante a sociedade.

Já o incentivo governamental está associado a questões de desempenho, ou seja, a forma como as organizações públicas formulam, planejam, implementam suas políticas públicas e controlam suas funções estatais visando o bem-estar social. A variável explicativa, comumente utilizada, é o tipo governamental (centralizado ou descentralizado), no qual as formas de administração pública mais gerenciais tendem a adotar melhores práticas de divulgação, pois os gestores são mais bem preparados em quesitos de administração que incluem as práticas de desempenho (Zimmerman, 1977). A variável auditoria interna também influencia o nível de divulgação da informação (qualitativa e quantitativa), principalmente, em termos de compliance (Giroux, 1989). Outra variável representativa é a burocracia pública ${ }^{5}$ que, de acordo com Giroux (1989), prefere baixos níveis de evidenciação para manter o poder e, consequentemente, uma monitoração ineficiente, tendendo a um efeito negativo nas práticas de evidenciação.

O incentivo social é associado ao contexto de pressão social (direito da sociedade) que influencia tanto a divulgação obrigatória como a voluntária. A fácil acessibilidade à informação pública estimula um melhor nível de evidenciação e reflete o comprometimento com a transparência e com a public accountability (Bakar e Saleh, 2011).

Por último, o incentivo financeiro com variáveis representativas, como a dependência federal e a receita governamental (mais empregadas nos estudos internacionais do setor público), indica que relativo à dependência federal, ${ }^{6}$ ao aplicar os recursos públicos, os gestores podem utilizá-los para propósitos pessoais diferenciados dos anseios e necessidades do cidadão. Logo, visando mitigar o conflito de agência, os normativos legais obrigam os gestores a um maior compliance com as práticas de evidenciação, condição para o recebimento dos recursos federais. Todavia, estudos (Bakar e Saleh, 2011; Martani e Lestiani, 2012) apontam que maiores ou menores graus de dependência federal não são um determinante para a entidade divulgar mais informação. Tal fato ocorre, provavelmente, porque as transferências federais não são baseadas em regras de compliance com padrões contábeis, mas sim automáticas. Sobre a variável receita governamental, as pesquisas anteriores (Laswad, Fisher e Oleyere, 2005; Martani e Lestiani, 2012) apontam uma influência positiva com o nível de evidenciação, possivelmente porque maiores níveis de receita aumentam a disposição dos gestores públicos em divulgar a informação, como forma de legitimidade perante a sociedade que contribui com os recursos.

Por fim, no contexto do setor público, não é surpreendente que os estudos cheguem a resultados diferenciados para determinadas variáveis, pois a diversidade de entidades governamentais, de objetivos e a dificuldade de coleta dos dados por vezes requerem o uso de

\footnotetext{
${ }^{5}$ No estudo, a variável burocracia pública deve ser entendida como cargos de assessoramento de livre nomeação e exoneração, de qualquer forma de provimento e, portanto, sujeitos a injunções burocráticas e políticas, e nesse contexto menores níveis de transparência podem favorecer a permanência no cargo.

${ }^{6}$ Nos estudos analisados, quadro 1 do item 2.3, a variável dependência federal representa as transferências federais que, no caso de alguns países que testaram a variável, são condicionadas ao cumprimento de regras de compliance.
} 
métricas e conceitos complementares aos utilizados em estudos similares. Logo, os estudos de evidenciação (disclosure) no setor público requerem maior reflexão acadêmica.

\subsection{Estudos anteriores sobre evidenciação, incentivos e variáveis no setor público}

O quadro 1 apresenta uma síntese dos estudos, utilizados na presente pesquisa, com foco no nível de evidenciação no setor público e na análise de incentivos que afetam a divulgação no setor público.

\section{Quadro 1}

\section{Síntese das pesquisas empíricas que abordam evidenciação no setor público}

\begin{tabular}{|c|c|c|c|c|}
\hline $\begin{array}{l}\text { Autor (ano) } \\
\text { País do } \\
\text { estudo }\end{array}$ & $\begin{array}{c}\text { Ente } \\
\text { (instrumento } \\
\text { de análise) }\end{array}$ & $\begin{array}{c}\text { Variável } \\
\text { dependente }\end{array}$ & $\begin{array}{l}\text { Incentivos: Variável } \\
\text { representativa } \\
\text { (sinais esperados) }\end{array}$ & Resultado \\
\hline $\begin{array}{l}\text { Zimmerman } \\
\text { (1977) } \\
\text { EUA }\end{array}$ & $\begin{array}{l}96 \text { cidades } \\
\text { (relatórios } \\
\text { anuais) }\end{array}$ & $\begin{array}{l}\text { Extensão do } \\
\text { relatório e } \\
\text { frequência de } \\
\text { auditoria }\end{array}$ & $\begin{array}{l}\text { Político: competição } \\
\text { política }(-)^{(2)} \\
\text { Social: mídia }(+)\end{array}$ & $\begin{array}{l}\text { A variável competição política apresentou relação } \\
\text { negativa, sugerindo que os baixos níveis de } \\
\text { evidenciação estariam associados ao desinteresse } \\
\text { dos eleitores no controle das funções estatais. } \\
\text { A mídia pode reduzir os conflitos de agência entre } \\
\text { agente (políticos) e principal (eleitores), visto } \\
\text { pressionar as organizações públicas a melhores } \\
\text { práticas de evidenciação. }\end{array}$ \\
\hline $\begin{array}{l}\text { Ingram } \\
(1984) \\
\text { EUA }\end{array}$ & $\begin{array}{l}50 \text { estados } \\
\text { (relatórios } \\
\text { anuais) }\end{array}$ & $\begin{array}{l}\text { Índice de } \\
\text { evidenciação }\end{array}$ & $\begin{array}{l}\text { Político: competição } \\
\text { política (+), nível } \\
\text { educacional }(0) \text {, } \\
\text { urbanização (+), renda } \\
\text { per capita }(+) \text { e porte } \\
(+) \text {. } \\
\text { Governamental: seleção } \\
\text { do auditor (0), sistema } \\
\text { contábil e administrativo } \\
\text { (+), profissionalismo (0) } \\
\text { Social: mídia }(-) \\
\text { Financeiro: dependência } \\
\text { federal (+), } \\
\text { endividamento }(0), \\
\text { receita governamental } \\
(+)\end{array}$ & $\begin{array}{l}\text { A dependência federal e a receita governamental } \\
\text { influenciam em melhores práticas de } \\
\text { evidenciação, entretanto, maiores ou menores } \\
\text { níveis de endividamento não afetam as práticas } \\
\text { de divulgação. A mídia, divergente da literatura, } \\
\text { aponta uma relação negativa, sugerindo uma } \\
\text { métrica inadequada ou que a divulgação da } \\
\text { informação pode acontecer mediante outras } \\
\text { formas (informativos e boletins). Basicamente, } \\
\text { todas as variáveis do incentivo político apontam } \\
\text { uma relação explicativa positiva com melhores } \\
\text { práticas de divulgação no setor público. Quanto } \\
\text { ao incentivo governamental, a seleção do sistema } \\
\text { contábil e administrativo melhora os níveis de } \\
\text { evidenciação, enquanto as demais variáveis não } \\
\text { interferem. }\end{array}$ \\
\hline $\begin{array}{l}\text { Giroux } \\
(1989) \\
\text { EUA }\end{array}$ & $\begin{array}{l}167 \text { cidades } \\
\text { (demonstrações } \\
\text { financeiras) }\end{array}$ & $\begin{array}{l}\text { Índice de } \\
\text { evidenciação } \\
\text { contábil }\end{array}$ & $\begin{array}{l}\text { Político: Competição } \\
\text { política }(0) \\
\text { Institucional: tipo de } \\
\text { governo }(+) \text {, burocracia } \\
(-) \\
\text { Governamental: } \\
\text { qualidade da auditoria } \\
\text { (-), regulamentação }(+) \\
\text { Financeiro: Receita }(+)\end{array}$ & $\begin{array}{l}\text { A burocracia apresentou resultados negativos } \\
\text { em relação às práticas de evidenciação, e a } \\
\text { correlação negativa da auditoria com melhores } \\
\text { práticas de divulgação seria a limitação que a } \\
\text { burocracia oferece ao monitoramento das ações } \\
\text { governamentais. A competição política não se } \\
\text { mostrou significativa, confirmando a falta de } \\
\text { interesse dos políticos em relação aos seus } \\
\text { eleitores. }\end{array}$ \\
\hline
\end{tabular}




\begin{tabular}{|c|c|c|c|c|}
\hline $\begin{array}{l}\text { Autor (ano) } \\
\text { País do } \\
\text { estudo }\end{array}$ & $\begin{array}{l}\text { Ente } \\
\text { (instrumento } \\
\text { de análise) }\end{array}$ & $\begin{array}{c}\text { Variável } \\
\text { dependente }\end{array}$ & $\begin{array}{l}\text { Incentivos: Variável } \\
\text { representativa } \\
\text { (sinais esperados) }\end{array}$ & Resultado \\
\hline $\begin{array}{l}\text { Cheng } \\
(1992) \\
\text { EUA }\end{array}$ & $\begin{array}{l}50 \text { Estados } \\
\text { (demonstrações } \\
\text { financeiras) }\end{array}$ & $\begin{array}{l}\text { Índice de } \\
\text { evidenciação } \\
\text { contábil } \\
\text { (atualização } \\
\text { do modelo } \\
\text { de Ingram, } \\
\text { 1984) }\end{array}$ & $\begin{array}{l}\text { Político: competição } \\
\text { política }(+), \text { força dos } \\
\text { grupos de interesse }(+), \\
\text { Poder Legislativo }(+) \\
\text { Social: mídia }(+) \\
\text { Econômico: } \\
\text { dívida (+), dependência } \\
\text { federal (+) } \\
\text { Institucional: burocracia } \\
(+) \\
\text { Governança: poder de } \\
\text { governança }(+)\end{array}$ & $\begin{array}{l}\text { A competição política, governança, mídia, dívida e } \\
\text { dependência federal explicam, de forma negativa, } \\
\text { o índice de evidenciação. } \\
\text { A burocracia e a força dos grupos de interesse } \\
\text { apresentaram relação positiva, enquanto o poder } \\
\text { legislativo não explica o índice. }\end{array}$ \\
\hline $\begin{array}{l}\text { Smith } \\
(2004) \\
\text { EUA }\end{array}$ & $\begin{array}{l}107 \text { Cidades } \\
\text { (demonstrações } \\
\text { financeiras) }\end{array}$ & $\begin{array}{l}\text { Índice } \\
\text { ponderado } \\
\text { de } \\
\text { evidenciação } \\
\text { voluntária de } \\
\text { desempenho: } \\
\text { orçamentário } \\
\text { e financeiro }\end{array}$ & $\begin{array}{l}\text { Político: competição } \\
\text { política }(+), \text { tipo de } \\
\text { governo }(+), \text { mídia }(+) \\
\text { Econômico: dívida }(+), \\
\text { auditoria interna }(+), \\
\text { receita }(+)\end{array}$ & $\begin{array}{l}\text { Embora as variáveis independentes mostrem-se } \\
\text { com significância (poder explicativo), apresentam- } \\
\text { se inconsistentes nos modelos, sugerindo uma } \\
\text { fraca explicação das mesmas ou inadequadas } \\
\text { utilizações das métricas. }\end{array}$ \\
\hline $\begin{array}{l}\text { Martani e } \\
\text { Lestiani } \\
\text { (2012) } \\
\text { Indonésia }\end{array}$ & $\begin{array}{l}92 \text { Municípios } \\
\text { (relatórios } \\
\text { financeiros) }\end{array}$ & $\begin{array}{l}\text { Índice de } \\
\text { evidenciação } \\
\text { financeiro }\end{array}$ & $\begin{array}{l}\text { Governamental: receita } \\
(+) \text {, dependência federal } \\
(+) \text {, porte }(+) \text {, achados } \\
\text { de auditoria }(-) \\
\text { Institucional: tipo de } \\
\text { governo }(+)\end{array}$ & $\begin{array}{l}\text { A receita, porte e achados da auditoria estimulam } \\
\text { melhores níveis de divulgação nos relatórios } \\
\text { financeiros, enquanto a dependência federal } \\
\text { e o tipo de governo não afetam as práticas de } \\
\text { divulgação dos municípios na Indonésia. }\end{array}$ \\
\hline $\begin{array}{l}\text { Ryan, } \\
\text { Stanley e } \\
\text { Nelson } \\
\text { (2002) } \\
\text { Austrália(1) }\end{array}$ & $\begin{array}{l}36 \text { Municípios } \\
\text { (relatórios } \\
\text { anuais) }\end{array}$ & $\begin{array}{l}\text { Índice de } \\
\text { evidenciação } \\
\text { contábil } \\
\text { ponderado }\end{array}$ & $\begin{array}{l}\text { Porte }(+) \text { e } \\
\text { tempestividade do } \\
\text { relatório }(+)\end{array}$ & $\begin{array}{l}\text { O porte influencia nas práticas de evidenciação, } \\
\text { enquanto a tempestividade do relatório não } \\
\text { mostrou relação com o disclosure. }\end{array}$ \\
\hline $\begin{array}{l}\text { Laswad, } \\
\text { Fisher e } \\
\text { Oleyere } \\
\text { (2005) } \\
\text { Nova } \\
\text { Zelândia(1) }\end{array}$ & $\begin{array}{l}61 \text { Órgãos } \\
\text { estatutários } \\
\text { (sites } \\
\text { eletrônicos) }\end{array}$ & $\begin{array}{l}\text { Índice } \\
\text { dicotômico } \\
\text { de } \\
\text { evidenciação } \\
\text { financeira } \\
\text { voluntária. } \\
\text { (sites com } \\
\text { informação } \\
\text { financeira e } \\
\text { sites sem) }\end{array}$ & $\begin{array}{l}\text { Competição política } \\
(+) \text {, porte }(+), \\
\text { endividamento }(+), \\
\text { receita }(+) \text {, mídia }(+) \text { e } \\
\text { tipo de governo }(-) \text {. }\end{array}$ & $\begin{array}{l}\text { Os resultados mostram uma inconsistência nos } \\
\text { dois modelos, apenas a mídia foi positivamente } \\
\text { relacionada aos índices de evidenciação, } \\
\text { ratificando a literatura de que a mídia contribuiria } \\
\text { para minimizar os conflitos de agência na } \\
\text { relação eleitor versus governante. Destaca, ainda, } \\
\text { como surpresa o fato de a variável porte, na } \\
\text { Nova Zelândia, não se relacionar aos índices, } \\
\text { contrariando as predições da literatura majoritária. }\end{array}$ \\
\hline $\begin{array}{l}\text { Maingot e } \\
\text { Zeghal } \\
\text { (2008) } \\
\text { Canadá(1) }\end{array}$ & $\begin{array}{l}44 \\
\text { Universidades } \\
\text { (sítio eletrônico) }\end{array}$ & $\begin{array}{l}\text { Índice de } \\
\text { evidenciação } \\
\text { voluntário } \\
\text { financeiro } \\
\text { e não } \\
\text { financeiro }\end{array}$ & Porte $(+)$, missão $(+)$ & $\begin{array}{l}\text { As variáveis resultaram numa relação positiva com } \\
\text { o índice sugerindo que, quanto mais complexa } \\
\text { a missão e maior o porte, melhor o nível de } \\
\text { evidenciação voluntário. }\end{array}$ \\
\hline
\end{tabular}




\begin{tabular}{|c|c|c|c|c|}
\hline $\begin{array}{l}\text { Autor (ano) } \\
\text { País do } \\
\text { estudo }\end{array}$ & $\begin{array}{l}\text { Ente } \\
\text { (instrumento } \\
\text { de análise) }\end{array}$ & $\begin{array}{c}\text { Variável } \\
\text { dependente }\end{array}$ & $\begin{array}{l}\text { Incentivos: Variável } \\
\text { representativa } \\
\text { (sinais esperados) }\end{array}$ & Resultado \\
\hline $\begin{array}{l}\text { Gandia e } \\
\text { Archidona } \\
\text { (2008) } \\
\text { Espanha(1) }^{(1)}\end{array}$ & $\begin{array}{l}130 \text { municípios } \\
\text { (sítios } \\
\text { eletrônicos) }\end{array}$ & $\begin{array}{l}\text { Índice de } \\
\text { evidenciação } \\
\text { ( } 6 \text { modelos) }\end{array}$ & $\begin{array}{l}\text { Competição política } \\
(+), \text { mídia }(+), \\
\text { endividamento }(+) \text { e } \\
\text { porte }(+)\end{array}$ & $\begin{array}{l}\text { Apenas a competição política e a mídia } \\
\text { explicaram melhores práticas de evidenciação em } \\
\text { todos os modelos, mas os resultados evidenciam } \\
\text { um baixo nível de evidenciação nos sites. }\end{array}$ \\
\hline $\begin{array}{l}\text { Perez, } \\
\text { Bolívar e } \\
\text { Hernandez } \\
\text { (2008) } \\
\text { Espanha(1) }^{(1)}\end{array}$ & $\begin{array}{l}65 \text { Municípios } \\
\text { (sítio eletrônico) }\end{array}$ & $\begin{array}{l}\text { Índice de } \\
\text { transparência } \\
\text { municipal }\end{array}$ & $\begin{array}{l}\text { Dívida (+), acessibilidade } \\
(+) \text {, competição política } \\
(+) \text {, receita }(+) \text { e } \\
\text { dependência federal }(+)\end{array}$ & $\begin{array}{l}\text { As variáveis dívida e acessibilidade apresentaram } \\
\text { relação positiva com o índice de transparência } \\
\text { municipal; as demais variáveis não explicam o } \\
\text { índice. }\end{array}$ \\
\hline $\begin{array}{l}\text { Bakar e } \\
\text { Saleh } \\
(2011) \\
\text { Malásia(1) }^{(1)}\end{array}$ & $\begin{array}{l}93 \text { órgãos } \\
\text { estatutários } \\
\text { (relatórios } \\
\text { anuais) }\end{array}$ & $\begin{array}{l}\text { Índice de } \\
\text { evidenciação }\end{array}$ & $\begin{array}{l}\text { Porte }(+) \text {, acessibilidade } \\
(+) \text {, dependência federal } \\
(+) \text { e tamanho da } \\
\text { diretoria }(-)\end{array}$ & $\begin{array}{l}\text { As variáveis porte e acessibilidade apresentam } \\
\text { relação positiva com o índice de evidenciação. } \\
\text { A variável dependência federal não foi } \\
\text { significativa, enquanto a variável tamanho da } \\
\text { diretoria apresentou relação negativa com o } \\
\text { índice de evidenciação. }\end{array}$ \\
\hline $\begin{array}{l}\text { Santana } \\
\text { Junior } \\
\text { (2008) } \\
\text { Brasil }\end{array}$ & $\begin{array}{l}207 \text { órgãos } \\
\text { estaduais } \\
\text { (sites } \\
\text { eletrônicos) }\end{array}$ & $\begin{array}{l}\text { Nível de } \\
\text { transparência } \\
\text { fiscal } \\
\text { eletrônica }\end{array}$ & $\begin{array}{l}\text { Indicadores econômicos } \\
\text { e sociais: receita total, } \\
\text { despesa total, resultado } \\
\text { nominal, resultado } \\
\text { primário, receita corrente } \\
\text { líquida, ativo real, passivo } \\
\text { real, dívida consolidada, } \\
\text { população, taxa de } \\
\text { alfabetização urbana, } \\
\text { renda per capita e } \\
\text { acessibilidade. }\end{array}$ & $\begin{array}{l}\text { Baixa aderência à transparência fiscal. Há } \\
\text { correlação dos indicadores econômicos e sociais } \\
\text { com a transparência fiscal. }\end{array}$ \\
\hline $\begin{array}{l}\text { Cruz (2010) } \\
\text { Brasil }\end{array}$ & $\begin{array}{l}100 \text { municípios } \\
\text { (sites } \\
\text { eletrônicos) }\end{array}$ & $\begin{array}{l}\text { Nível de } \\
\text { transparência } \\
\text { municipal }\end{array}$ & $\begin{array}{l}\text { Indicadores econômicos } \\
\text { e sociais: região, } \\
\text { localização, partido, } \\
\text { acessibilidade, PIB } \\
\text { per capita, receita } \\
\text { orçamentária, IDH-M, } \\
\text { taxa de alfabetização, } \\
\text { índice Firjan-M, } \\
\text { IPC, índice de } \\
\text { responsabilidade fiscal, } \\
\text { dinamismo municipal. }\end{array}$ & $\begin{array}{l}\text { Média geral: o ITGP foi } 66 \% \text {. Correlação positiva e } \\
\text { significativa para as variáveis receita orçamentária } \\
\text { e dinamismo municipal. }\end{array}$ \\
\hline
\end{tabular}

Fonte: Elaborado pelos autores (2013).

Notas: (1) Esses autores não utilizaram incentivos associados às variáveis independentes estudadas. (2) Os sinais esperados são descritos ao lado de cada variável: (+) relação positiva com a variável dependente; (-) relação negativa com a variável dependente e (0) indica que não afeta a variável dependente.

Os estudos descritos avaliam a divulgação da informação a partir de diversos instrumentos (web sites, relatórios anuais, demonstrações financeiras, relatórios fiscais) e, embora com diferentes objetivos, todos são relevantes no que tange a transparência pública. 
Os estudos internacionais que utilizam sites eletrônicos entendem a comunicação tecnológica (e-government) como uma ferramenta para guiar o relacionamento do Estado com seus usuários, atender demandas sociais, promover a responsabilização pública e, em nível internacional, uma possibilidade de benchmarking entre as organizações do setor público no que tange às boas práticas de evidenciação.

Os estudos internacionais que utilizam demonstrações financeiras pretendem investigar o nível de divulgação quanto ao atendimento, pelos governos locais, aos padrões contábeis aceitos (Ipsas). Por último, os estudos internacionais que utilizam relatórios anuais percebem estes como importantes mecanismos de responsabilização pública e transparência, por abrangerem toda a gestão pública (orçamentária, financeira, resultados, pessoal, patrimonial). Nesse aspecto, no cenário brasileiro, os relatórios de gestão anuais, exigidos nas prestações de contas, são os instrumentos legais de responsabilização pública a abordar todos os aspectos da gestão pública.

Já os estudos nacionais ${ }^{7}$ focam portais eletrônicos como instrumentos de acessibilidade e acompanhamento da aplicação dos recursos públicos, ou seja, o controle social e, assim, ferramentas para redução do déficit de accountability.

Os autores do quadro 1 reconhecem nos estudos internacionais certas limitações como: (i) subjetividade inerente à construção de índice de evidenciação; (ii) poucas variáveis independentes; (iii) dificuldade na seleção das proxies, ocasionando variabilidade dos resultados para explicar os modelos de índice; (iv) não segregação entre itens obrigatórios e voluntários; (v) poucos estudos que explicitam a associação entre os incentivos e as variáveis representativas; e (vi) ausência de uma linha teórica mais consistente que possa explicar as nuances da divulgação da informação no setor público.

\section{Metodologia}

Para alcançar o objetivo da pesquisa optou-se por uma abordagem empírico-analítica para realização dos testes de hipóteses com corte transversal (cross sectional) e investigação ex post facto, dos quais o pesquisador não pode controlar nem manipular as variáveis.

\subsection{Seleção da amostra}

Para composição da amostra partiu-se da população de entidades públicas ${ }^{8}$ federais, do Poder Executivo, que apresentaram relatório de gestão em 2010. A tabela 1 indica a população

\footnotetext{
${ }^{7}$ Lock (2003); Sacramento e Pinho (2007); Santana Junior (2008); Paiva e Zuccolotto (2009); Cruz (2010).

${ }^{8}$ Abrangem autarquias, fundações e órgãos públicos, embora este último sem personalidade jurídica própria desempenha função estatal, imputada a pessoa jurídica a que pertence, que, no caso federal, é a União.
} 
e a amostra probabilística estratificada composta de 115 entidades, sendo 37 autarquias, 14 fundações e 64 órgãos públicos. O foco em relatórios de gestão anuais baseou-se no consenso de estudos internacionais anteriores que consideram os relatórios anuais como fontes de consolidação de abordagem, financeira, orçamentária, resultados, controles, pessoal, patrimonial e outras, da informação pública (Bakar e Saleh, 2011; Tooley, Hooks e Basnan, 2010). Após a seleção da amostra, os dados necessários para a pesquisa foram, manualmente, coletados e tabulados.

Tabela 1

Definição da amostra

\begin{tabular}{|lcc|}
\hline Painel 1: Composição da População & Quantidade & $\%$ \\
\hline Entidades públicas disponíveis na base de dados ${ }^{1}$ & 1075 & $100,0 \%$ \\
Entidades públicas militares ${ }^{2}$ & $(458)$ & $(42,6 \%)$ \\
Entidades públicas descentralizadas & $(286)$ & $(26,6 \%)$ \\
Total de entidades públicas para estudo & 331 & $30,8 \%$ \\
\hline
\end{tabular}

\begin{tabular}{|c|c|c|c|c|c|}
\hline \multicolumn{6}{|c|}{ Painel 2: Estratificação da população e seleção da amostra } \\
\hline \multirow[b]{2}{*}{ Natureza da Entidade } & \multicolumn{2}{|c|}{ Total de Entidades Públicas } & \multicolumn{2}{|c|}{ Amostra } & \multirow[b]{2}{*}{$\begin{array}{c}\text { Relação } \\
\text { (b/a) }\end{array}$} \\
\hline & Quant. (a) & $\%$ & $\begin{array}{l}\text { Quant. } \\
\text { (b) }\end{array}$ & $\%$ & \\
\hline Autarquia & 106 & $32 \%$ & 37 & $32 \%$ & $35 \%$ \\
\hline Fundação & 40 & $12 \%$ & 14 & $12 \%$ & $35 \%$ \\
\hline Órgão público & 185 & $56 \%$ & 64 & $56 \%$ & $35 \%$ \\
\hline Total & 331 & $100 \%$ & 115 & $100 \%$ & $35 \%$ \\
\hline
\end{tabular}

Fonte: Elaborada pelos autores (2013).

Notas: (1) Dados obtidos na base de dados contas públicas (relatórios de gestão 2010) do site do TCU. Entidades públicas da administração pública direta e indireta que devem encaminhar relatório de gestão anual definidos na Instrução Normativa TCU no 107/2010; (2) As entidades públicas militares (Forças Armadas), devido à peculiaridade das suas funções, e as entidades públicas descentralizadas, por serem representadas pelos seus órgãos centrais, foram excluídas da base de dados.

\subsection{Análise dos dados}

A análise dos dados envolveu a construção de um índice de transparência pública federal (ITPF) com uma abordagem dicotômica e ponderada baseado, exclusivamente, no conteúdo dos relatórios de gestão anuais. Para tanto, foi realizada uma revisão de literatura, nacional e internacional, que abordasse índices de transparência pública e, mais especificamente, que utilizasse relatórios anuais para a coleta de dados. Nesse levantamento, seis modelos 
internacionais ${ }^{9}$ foram selecionados, bem como os normativos legais (Instrução Normativa TCU no 63/2010 e Decisões Normativas TCU no 107/2010 e no 110/2010) que regem a divulgação das informações, nos relatórios de gestão anuais, da administração pública federal. Após a identificação dos modelos foi conduzido um pré-teste, ${ }^{10}$ visando verificar a aplicabilidade ao cenário nacional. Com base nesse pré-teste foi selecionado o modelo proposto por Bakar e Saleh (2011) como referência, por ser o mais completo. Naturalmente, foram realizadas algumas adaptações para adequação ao contexto brasileiro, bem como incorporação de poucos itens adicionais previstos nos outros modelos.

O ITPF é composto de 112 itens de evidenciação (26 subcategorias e cinco categorias), segregados em obrigatórios (52 itens), baseado na legislação de prestação de contas, e voluntários (60 itens), baseado nos modelos de referência. A mensuração do ITPF de cada entidade é a razão do total de itens que efetivamente foram divulgados, no relatório de gestão, sobre o total de itens teoricamente aplicáveis à entidade. Logo, o ITPF é representado pelas seguintes expressões matemáticas:

$$
\begin{gathered}
\text { Índice Dicotômico: ITPF }=\frac{\sum d_{i}}{n} \\
\text { Índice Ponderado: ITPF }=\frac{\sum d_{i} P_{i}}{n}
\end{gathered}
$$

Onde: ITPF $=$ total de itens divulgados para a entidade; $\mathbf{d} i=1$, se o item i for divulgado; 0 , contrário; $\mathbf{p}$ = relevância atribuída baseada na média aritmética; $\mathbf{n}=$ número de itens teoricamente aplicáveis à entidade.

A abordagem de pontuação do índice ponderado (peso) foi apurada com base na opinião ${ }^{11}$ de analistas de finanças e controle, ${ }^{12}$ da Controladoria Geral da União (CGU). Por conseguinte, a pontuação máxima em cada método é a seguinte: no dicotômico, - 112, e, no ponderado, - 430 .

A análise univariada consistiu em testes de diferenças de média (paramétricos e não paramétricos), respectivamente para amostras independentes (entidades públicas) e parea-

\footnotetext{
${ }^{9}$ Os estudos selecionados foram: (1) Bakar e Saleh (2011), (2) Herataway e Hoque (2007), (3) Coy e Dixon (2004), (4) Wei, Davey e Coy (2008), (5) Ryan, Stanley e Nelson (2002) e (6) Lim e Mckinnon (1993). A escolha dos modelos internacionais se justifica por serem bem abrangentes quanto à evidenciação no setor público e pela ausência de estudos nacionais de análise do nível de transparência pública com foco em relatórios anuais.

${ }^{10}$ Foram analisadas, integralmente, as listas de itens de evidenciação (itens, subcategorias e categorias) propostas nos seis modelos, para a coleta nos relatórios de gestão de 2010 de seis entidades públicas federais.

${ }^{11}$ Essa opinião foi capturada via um questionário analítico fechado, que avaliou a relevância dos 112 itens, utilizando uma escala de Likert de 5 (cinco) pontos, sendo 1 (um) para sem relevância e 5 (cinco) para muito relevante.

${ }^{12}$ A amostra de respondentes (probabilística) de aproximadamente 2\% (dois) da população, de 2.224 analistas, totalizou 40 analistas. O questionário foi disponibilizado via rede institucional e as respostas obtidas totalizaram 35 (87,5\% da amostra total). O quantitativo populacional de servidores da GCU foi obtido em 30/06/2012 através do site Portal da Transparência.
} 
das (índice dicotômico e ponderado), bem como na realização de testes de correlação. Para a normalidade das variáveis foi realizado o teste de Kolmogorov-Smirnov e, consequentemente, validado o teste estatístico mais adequado para cada variável. Assim os testes estatísticos consistiram na análise das seguintes hipóteses:

$\mathbf{H}_{\mathrm{a}}$ : Não existe diferença no nível de transparência pública federal (ITPF) dicotômico e ponderado.

$\mathbf{H}_{\mathrm{b}}$ : Não existe diferença no nível de transparência pública federal (ITPF) entre as entidades públicas.

Em seguida, a análise multivariada utilizou regressão linear múltipla, com dados em corte transversal de 2010, que permitiu analisar a relação existente entre a variável dependente quantitativa (ITPF) e as variáveis explicativas (independentes) descritas no quadro 2. O modelo utilizado no estudo foi:

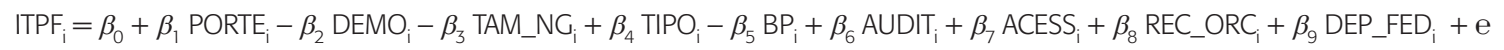

Onde: $\mathbf{I T P F}=$ variável dependente quantitativa (proxy empregada é o escore de cada entidade governamental); $\mathbf{i}=$ entidade pública federal; as variáveis explicativas (independentes) estão indicadas no quadro 2.

Destaca-se que algumas variáveis podem captar aspectos complementares (aplicabilidade e acessibilidade) para melhor adaptação ao setor público brasileiro. E os sinais esperados são baseados nos achados de estudos internacionais anteriores; logo, estes podem não ser aplicáveis ao contexto brasileiro. Assim, a hipótese testada na análise multivariada:

$\mathbf{H}_{\mathbf{c}}$ : Não há correlação entre o nível de transparência pública federal divulgada nos relatórios de gestão em relação ao porte (incentivo político), em relação ao tamanho do núcleo de gestão e demografia pessoal (incentivo institucional), em relação ao tipo da entidade, auditoria interna e burocracia pública (incentivo governamental), em relação à acessibilidade (incentivo social) e em relação à receita orçamentária e à dependência federal (incentivo financeiro).

Quadro 2

Descrição operacional dos incentivos para divulgação da informação

\begin{tabular}{|c|c|c|c|}
\hline 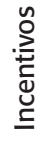 & $\begin{array}{l}\text { Variável (Sigla) (Sinal } \\
\text { esperado) }\end{array}$ & Proxy & Descrição da variável \\
\hline 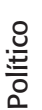 & $\begin{array}{l}\text { Tamanho da entidade } \\
\text { (Porte) }(+)^{1}\end{array}$ & Número de empregados & $\begin{array}{l}\text { Logaritmo do número de empregados da } \\
\text { entidade }\end{array}$ \\
\hline \multirow{2}{*}{ 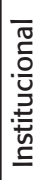 } & $\begin{array}{l}\text { Demografia pessoal } \\
(\text { Demo) (?) }\end{array}$ & Custo de pessoal por empregado & $\begin{array}{l}\text { Custo de pessoal dividido pelo número de } \\
\text { empregados }\end{array}$ \\
\hline & $\begin{array}{l}\text { Tamanho do núcleo de gestão } \\
\text { (Tam_ng) (-) }\end{array}$ & Quantitativo do núcleo de gestão & $\begin{array}{l}\text { Membros do núcleo de gestão (dirigente e } \\
\text { quantitativo de cargo em comissão subordinados) }\end{array}$ \\
\hline
\end{tabular}

Continua 


\begin{tabular}{|c|c|c|c|}
\hline 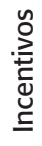 & $\begin{array}{l}\text { Variável (Sigla) (Sinal } \\
\text { esperado) }\end{array}$ & Proxy & Descrição da variável \\
\hline \multirow{3}{*}{ 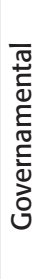 } & $\begin{array}{l}\text { Burocracia Pública } \\
(\mathrm{BP})(-)\end{array}$ & $\begin{array}{l}\text { Cargos em comissão em relação ao } \\
\text { número de empregados }\end{array}$ & $\begin{array}{l}\text { Total de cargos em comissão dividido pelo } \\
\text { número de empregados }\end{array}$ \\
\hline & $\begin{array}{l}\text { Tipo da entidade } \\
\text { (Tipo) }(+)\end{array}$ & $\begin{array}{l}\text { Tipo administrativo (direta ou } \\
\text { indireta) }\end{array}$ & $\begin{array}{l}\text { Variável do tipo dummy, onde } 0=\text { direta e } 1= \\
\text { indireta }\end{array}$ \\
\hline & $\begin{array}{l}\text { Auditoria interna } \\
\text { (Audit) }(+)\end{array}$ & $\begin{array}{l}\text { Existência da função de auditoria } \\
\text { interna na entidade }\end{array}$ & $\begin{array}{l}\text { Variável dummy, sendo } 1=\text { com auditoria } \\
\text { interna e } 0=\text { sem auditoria interna }\end{array}$ \\
\hline $\begin{array}{l}\bar{\pi} \\
\text { i } \\
\text { i }\end{array}$ & $\begin{array}{l}\text { Acessibilidade } \\
\text { (Acess) }(+)\end{array}$ & $\begin{array}{l}\text { Divulgação do relatório de gestão no } \\
\text { site da entidade }\end{array}$ & $\begin{array}{l}\text { Variável dummy, sendo } 1=\text { disponível e } 0=\text { não } \\
\text { disponível. }\end{array}$ \\
\hline \multirow{2}{*}{ 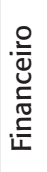 } & $\begin{array}{l}\text { Dependência federal } \\
\text { (Dep_fed) }(+)\end{array}$ & Transferências federais de recursos & $\begin{array}{l}\text { Transferência orçamentária dividida pela receita } \\
\text { orçamentária }\end{array}$ \\
\hline & $\begin{array}{l}\text { Receita orçamentária (Rec_orc) } \\
(+)\end{array}$ & $\begin{array}{l}\text { Receita orçamentária (receitas } \\
\text { próprias + transferências) }\end{array}$ & $\begin{array}{l}\text { Logaritmo da receita orçamentária (próprias e } \\
\text { transferências) }\end{array}$ \\
\hline
\end{tabular}

Fonte: Elaborado pelos autores (2013).

Notas: (1) Os sinais esperados são: (+) aumenta o nível de transparência, (?) sem previsão e (-) diminui o nível de transparência.

\section{Resultados}

\subsection{Análise preliminar das práticas de transparência pública por tipo de índice}

A tabela 2 apresenta os índices de transparência (total, obrigatório e voluntário) das entidades governamentais. O índice médio total é 48\% (dicotômico) e 50\% (ponderado), ou seja, divulgação média de 53 itens dos 112. Esse resultado é consistente com estudos anteriores, como Bakar e Saleh (2011), com um índice dicotômico de 46\% (Malásia), porém inferior aos achados de Herawaty e Hoque (2007), com um índice dicotômico de 61,5\% (Austrália), e Wei, Davey e Coy (2008), com um índice dicotômico de 61\% (Inglaterra e Nova Zelândia).

Contudo, a característica-chave do ITPF total é sua distribuição significativamente dispersa. E essa variabilidade é nitidamente percebida na análise da amostra estratificada: (a) órgãos públicos (administração direta) apresentam os menores índices de evidenciação com maior variabilidade (27\% a 62\%); (b) fundações (administração indireta) mostram uma variabilidade de divulgação de $42 \%$ a $70 \%$; e (c) autarquias (administração indireta), com uma variação de $39 \%$ a 74\%. Assim, o ITPF total aponta uma proximidade nas práticas de evidenciação pública entre as autarquias e as fundações, enquanto os órgãos públicos apresentam um maior distanciamento. Essa situação sugere que a administração pública indireta federal (autarquias e fundações), com características mais gerenciais e técnicas e mais distante do 
núcleo de poder, propicia melhores práticas de evidenciação, enquanto os órgãos públicos, administração direta, com características mais políticas e burocráticas, tendem a divulgar menos informação.

Os resultados são consistentes com Marcuccio e Stecollini (2008), ao apontarem que tipos governamentais mais próximos ao cidadão, seja pela prestação de serviços públicos, ou por atividades regulatórias, são mais gerenciais e com melhores níveis de evidenciação, qualitativa e quantitativa, nos relatórios de gestão. Nesse sentido, as autarquias e fundações que exercem atividades regulatórias (agências reguladoras), educacionais (universidades), sociais (Funai, Fiocruz etc.) e culturais (Funarte, Biblioteca Nacional etc.) são melhor identificadas pelo cidadão e, sob esse aspecto, podem afetar, positivamente, as práticas de evidenciação dessas entidades. Já os órgãos públicos, formuladores de políticas públicas, tendem a ser menos transparentes nas práticas de evidenciação.

O índice de transparência pública obrigatória (80\%) revela que as entidades governamentais federais são mais influenciadas pelas práticas de divulgação obrigatória (órgão público: $75 \%$, autarquia: $87 \%$ e fundação: $89 \%$ ), exigidas pela legislação de prestação de contas, do que as práticas de divulgação voluntária (painel 1 da tabela 4). Os resultados são similares aos de Martani e Lestiani (2012) ao relatarem que, no setor público, os instrumentos mandatórios de evidenciação, quando exigidos pelo legislativo, compelem os governantes a serem mais transparentes e, consequentemente, afetam positivamente as práticas de evidenciação.

Contudo, ressalta-se que o índice de evidência obrigatório (ITPF obrigatório) ainda é baixo, pois todos os itens deveriam estar integralmente presentes em todas as entidades públicas federais. No entanto, se observam variações no índice de evidenciação obrigatório de 100\% (fundação) a 45\% (órgão público). Assim, por exemplo, enquanto um órgão público divulgou apenas 24 itens, do total dos 52 itens obrigatórios, por outro lado, apenas uma fundação divulgou todos os itens. Por conseguinte, explicita que a legislação vigente de divulgação obrigatória não está sendo, totalmente, cumprida e pode provocar limitação quanto à responsabilização nas prestações de contas das organizações governamentais.

O ITPF médio voluntário de 19\% se mostrou expressivamente baixo, ou seja, em média, 11 itens dos 60 foram divulgados. Entretanto, é similar a estudos anteriores como de Steccolini (2002) e Maingot e Zeghal (2008), ambos, respectivamente, com um índice voluntário de 19\% para 30 municípios italianos e 44 universidades no Canadá. Mas, inferior aos achados de Herataway e Hoque (2007) e Lim e Mckinnon (1993), ambos na Austrália, com índices de $65 \%$ e $56 \%$, respectivamente.

Notadamente, o painel 1 da tabela 2 permite visualizar que as entidades públicas divulgam menos informações voluntárias ao cidadão acerca da aplicação dos recursos públicos, pois a dispersão média do índice de evidenciação voluntário entre as entidades foi a menor (órgão público: com nível médio de divulgação voluntária de 16\%, autarquias e fundações: com nível médio de divulgação voluntário de $23 \%$ ). No entanto, quando analisados, separadamente, casos específicos de melhores índices voluntários como 51\% (autarquias) e 45\% (fundações) sinalizam perspectivas de mudanças. 
Tabela 2

Estatística descritiva das variáveis dependentes quantitativas da amostra total e estratificada

\begin{tabular}{|c|c|c|c|c|c|c|c|c|c|c|c|c|}
\hline \multicolumn{13}{|c|}{ Painel 1: Índice de transparência pública federal dicotômico e ponderado ${ }^{3}$} \\
\hline \multicolumn{13}{|c|}{ Dicotômico' } \\
\hline & \multicolumn{4}{|c|}{ Total } & \multicolumn{4}{|c|}{ Obrigatório $^{2}$} & \multicolumn{4}{|c|}{ Voluntário $^{2}$} \\
\hline & $\frac{.00}{\frac{\pi}{0}}$ & 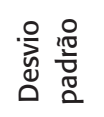 & 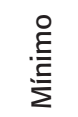 & 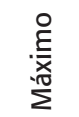 & 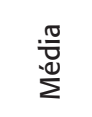 & 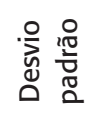 & 站 & 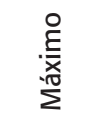 & $\sum^{\frac{\pi}{\pi}}$ & 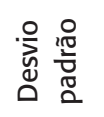 & 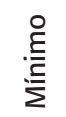 & 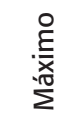 \\
\hline Total & $48 \%$ & $8 \%$ & $26 \%$ & $71 \%$ & $81 \%$ & $11 \%$ & $46 \%$ & $100 \%$ & $19 \%$ & $9 \%$ & $2 \%$ & $48 \%$ \\
\hline Autarquia & $53 \%$ & $8 \%$ & $38 \%$ & $71 \%$ & $87 \%$ & $7 \%$ & $65 \%$ & $98 \%$ & $23 \%$ & $10 \%$ & $3 \%$ & $48 \%$ \\
\hline Fundação & $54 \%$ & $7 \%$ & $42 \%$ & $68 \%$ & $89 \%$ & $6 \%$ & $79 \%$ & $100 \%$ & $22 \%$ & $9 \%$ & $8 \%$ & $43 \%$ \\
\hline Órgão Público & $45 \%$ & $7 \%$ & $26 \%$ & $60 \%$ & $75 \%$ & $10 \%$ & $46 \%$ & $96 \%$ & $16 \%$ & $6 \%$ & $2 \%$ & $32 \%$ \\
\hline \multicolumn{13}{|c|}{ Ponderado ${ }^{1}$} \\
\hline Total & $50 \%$ & $9 \%$ & $27 \%$ & $74 \%$ & $80 \%$ & $12 \%$ & $45 \%$ & $100 \%$ & 19\% & $9 \%$ & $2 \%$ & $51 \%$ \\
\hline Autarquia & $54 \%$ & $8 \%$ & $39 \%$ & $74 \%$ & $87 \%$ & $8 \%$ & $64 \%$ & $98 \%$ & $23 \%$ & $10 \%$ & $4 \%$ & $51 \%$ \\
\hline Fundação & $55 \%$ & $7 \%$ & $42 \%$ & $70 \%$ & $89 \%$ & $6 \%$ & $77 \%$ & $100 \%$ & $23 \%$ & $10 \%$ & $8 \%$ & $45 \%$ \\
\hline Órgão Público & $46 \%$ & $7 \%$ & $27 \%$ & $62 \%$ & $74 \%$ & $11 \%$ & $45 \%$ & $96 \%$ & $16 \%$ & $7 \%$ & $2 \%$ & $32 \%$ \\
\hline \multicolumn{13}{|c|}{ Painel 2: Quantitativo de itens divulgados } \\
\hline & \multicolumn{4}{|c|}{ Total } & \multicolumn{4}{|c|}{ Obrigatório } & \multicolumn{4}{|c|}{ Voluntário } \\
\hline & $\frac{.00}{\frac{\pi}{0.0}}$ & 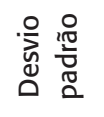 & 趇 & 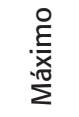 & $\frac{.00}{\frac{\pi}{\pi}}$ & 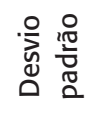 & 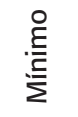 & 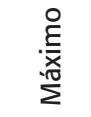 & : & 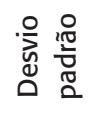 & 写 & 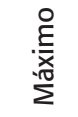 \\
\hline Total & 53 & 10 & 28 & 82 & 42 & 6 & 24 & 52 & 11 & 5 & 1 & 31 \\
\hline Autarquia & 59 & 9 & 42 & 82 & 45 & 4 & 34 & 51 & 14 & 6 & 2 & 31 \\
\hline Fundação & 60 & 8 & 48 & 76 & 47 & 3 & 41 & 52 & 14 & 6 & 6 & 26 \\
\hline Órgão Público & 48 & 8 & 28 & 66 & 39 & 6 & 24 & 50 & 10 & 4 & 1 & 19 \\
\hline
\end{tabular}

Fonte: Elaborada pelos autores (2013).

Nota: (1) ITPF dicotômico é o índice binário ( $1=$ presença e $0=$ ausência do item); ITPF ponderado é o índice binário agregado à relevância média dos itens. (2) Obrigatórios são os itens obrigatórios divulgados divididos pelo total de itens obrigatórios; Voluntários são os itens voluntários divulgados divididos pelo total de itens voluntários. (3) A pontuação máxima do índice dicotômico é 112, enquanto o ponderado é 430 . 
No cenário apresentado se confirma que o setor público brasileiro ainda é resistente à divulgação da informação voluntária e que o gestor governamental está mais inclinado em atender, ainda que de forma incompleta, as práticas de evidenciação obrigatória, cujo não cumprimento impõe sanções legais (apuração de responsabilidade e ressalva nas prestações de contas) aplicáveis pelos órgãos de controle (CGU e TCU). Enquanto as práticas de evidenciação voluntária da regular aplicação dos recursos públicos ainda possuem espaço para significativas melhorias.

\subsection{Análise qualitativa da transparência pública}

A tabela 3 apresenta os itens de divulgação pública, por categoria e subcategoria, nos 115 relatórios de gestão anuais de 2010. Observa-se que 4 categorias, de 5, alcançaram uma divulgação abaixo de 50\%, relativo aos potenciais itens de divulgação, confirmando a baixa transparência da informação no setor público brasileiro.

Tabela 3

\section{Análise da composição do índice de transparência pública federal por subcategoria e categoria}

\begin{tabular}{|c|c|c|c|c|c|c|c|c|c|c|c|}
\hline & \multirow{2}{*}{ Subcategoria de evidenciação } & \multicolumn{3}{|c|}{ Total Possível (a) } & \multicolumn{3}{|c|}{$\begin{array}{c}\text { Total } \\
\text { divulgado(b) }\end{array}$} & \multicolumn{4}{|c|}{ Relação (b/a) } \\
\hline & & $\begin{array}{l}\bar{\pi} \\
\text { 夰 }\end{array}$ & 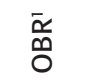 & $\stackrel{-}{\ominus}$ & $\begin{array}{l}\bar{\pi} \\
\text { 苟 }\end{array}$ & $\begin{array}{l}\frac{\alpha}{\infty} \\
0\end{array}$ & $\vec{\rho}$ & 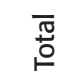 & $\begin{array}{l}\frac{\alpha}{0} \\
0\end{array}$ & $\vec{\rho}$ & $\sum_{\alpha}^{M}$ \\
\hline 1 & Histórico do relatório de gestão & 345 & 345 & 0 & 291 & 291 & 0 & 0,84 & 0,84 & 0 & 3,99 \\
\hline 2 & Acesso à informação & 460 & 345 & 115 & 345 & 345 & 0 & 0,75 & 1,00 & 0 & 3,11 \\
\hline 3 & Histórico do órgão & 690 & 690 & 0 & 635 & 635 & 0 & 0,92 & 0,92 & 0 & 3,39 \\
\hline 4 & Objetivo do órgão & 460 & 230 & 230 & 264 & 157 & 107 & 0,57 & 0,68 & 0,46 & 3,65 \\
\hline 5 & Informação Corporativa & 805 & 345 & 460 & 477 & 163 & 205 & 0,59 & 0,47 & 0,45 & 3,80 \\
\hline 6 & Mensagem sobre a gestão & 805 & 345 & 460 & 421 & 291 & 130 & 0,52 & 0,84 & 0,28 & 3,88 \\
\hline \multirow[t]{2}{*}{7} & Diretoria ou equivalente & 230 & 0 & 230 & 48 & 0 & 48 & 0,21 & 0 & 0,21 & 3.09 \\
\hline & Categoria Geral & 3795 & 2300 & 1380 & 2481 & 1882 & 490 & 0,65 & 0,82 & 0,35 & 3,62 \\
\hline 8 & Governança da diretoria ou equivalente & 920 & 0 & 920 & 36 & 0 & 36 & 0,04 & 0 & 0,04 & 2,83 \\
\hline 9 & Auditoria Interna² & 51 & 0 & 51 & 1 & 0 & 1 & 0,02 & 0 & 0,02 & 3,85 \\
\hline \multirow[t]{2}{*}{10} & Controles Internos & 115 & 115 & 0 & 100 & 100 & 0 & 0,87 & 0,87 & 0 & 4,70 \\
\hline & Categoria Governança & 1086 & 115 & 971 & 137 & 100 & 37 & 0,13 & 0,87 & 0,04 & 3,19 \\
\hline 11 & Demonstrações financeiras & 115 & 0 & 115 & 10 & 0 & 10 & 0,09 & 0 & 0,09 & 4,52 \\
\hline 12 & Certificado financeiro & 345 & 115 & 230 & 153 & 114 & 39 & 0,44 & 0,99 & 0,17 & 4,17 \\
\hline
\end{tabular}




\begin{tabular}{|c|c|c|c|c|c|c|c|c|c|c|c|}
\hline & \multirow{2}{*}{ Subcategoria de evidenciação } & \multicolumn{3}{|c|}{ Total Possível (a) } & \multicolumn{3}{|c|}{$\begin{array}{c}\text { Total } \\
\text { divulgado(b) }\end{array}$} & \multicolumn{4}{|c|}{ Relação (b/a) } \\
\hline & & $\begin{array}{l}\overline{0} \\
\stackrel{0}{\circ}\end{array}$ & $\begin{array}{l}\bar{\alpha} \\
\text { o }\end{array}$ & $\bar{\rho}$ & $\begin{array}{l}\overline{0} \\
0 \\
0\end{array}$ & $\begin{array}{l}\stackrel{\alpha}{\circ} \\
\stackrel{\tilde{O}}{0}\end{array}$ & $\vec{\rho}$ & $\begin{array}{l}\overline{0} \\
\stackrel{0}{0}\end{array}$ & $\begin{array}{l}\stackrel{\circ}{0 口} \\
\stackrel{0}{0}\end{array}$ & $\vec{\rho}$ & $\sum_{\alpha=}^{m}$ \\
\hline \multirow[t]{2}{*}{13} & $\begin{array}{l}\text { Análise do desempenho do orçamentário } \\
\text { e financeiro }\end{array}$ & 805 & 345 & 460 & 311 & 257 & 54 & 0,39 & 0,74 & 0,12 & 4,20 \\
\hline & Categoria Financeira & 1265 & 460 & 805 & 474 & 371 & 103 & 0,37 & 0,81 & 0,13 & 4,22 \\
\hline 14 & Indicadores de desempenho & 460 & 460 & 0 & 270 & 270 & 0 & 0,59 & 0,59 & 0 & 4,33 \\
\hline 15 & $\begin{array}{l}\text { Indicador de satisfação: usuário/ } \\
\text { empregado }\end{array}$ & 460 & 0 & 460 & 82 & 0 & 82 & 0,18 & 0 & 0,18 & 4,05 \\
\hline 16 & Visão geral dos programas governamentais & 690 & 460 & 230 & 408 & 334 & 74 & 0,59 & 0,73 & 0,32 & 4,21 \\
\hline \multirow[t]{2}{*}{17} & $\begin{array}{l}\text { Desempenho dos programas } \\
\text { governamentais }\end{array}$ & 1495 & 575 & 920 & 604 & 452 & 152 & 0,40 & 0,79 & 0,16 & 4,26 \\
\hline & Categoria Desempenho & 3105 & 1035 & 1610 & 1364 & 786 & 308 & 0,44 & 0,76 & 0,19 & 4,23 \\
\hline 18 & Recursos humanos & 1495 & 575 & 920 & 687 & 493 & 194 & 0,46 & 0,86 & 0,21 & 3,80 \\
\hline 19 & Informação socioambiental & 460 & 115 & 345 & 168 & 95 & 73 & 0,37 & 0,83 & 0,21 & 3,58 \\
\hline 20 & Principais ativos & 460 & 345 & 115 & 223 & 223 & 0 & 0,48 & 0,65 & 0 & 3,41 \\
\hline 21 & Compras & 115 & 0 & 115 & 24 & 0 & 24 & 0,21 & 0 & 0,21 & 3,85 \\
\hline 22 & Consultores & 230 & 0 & 230 & 65 & 0 & 65 & 0,28 & 0 & 0,28 & 3,98 \\
\hline 23 & Licitações e contratos & 230 & 230 & 0 & 209 & 209 & 0 & 0,91 & 0,91 & 0 & 4,45 \\
\hline 24 & Transferências & 115 & 115 & 0 & 88 & 88 & 0 & 0,77 & 0,77 & 0 & 4,45 \\
\hline 25 & Tecnologia da informação & 115 & 115 & 0 & 99 & 99 & 0 & 0,86 & 0,86 & 0 & 4,15 \\
\hline 26 & Outras informações & 230 & 115 & 115 & 103 & 94 & 9 & 0,45 & 0,82 & 0,08 & 4,06 \\
\hline & Categoria Outros & 3450 & 1610 & 1840 & 1666 & 1301 & 365 & 0,48 & 0,81 & 0,19 & 3,80 \\
\hline
\end{tabular}

Fonte: Elaborada pelos autores (2013).

Nota: (1) OBR: item de evidenciação obrigatório; VOL: item de evidenciação voluntário. (2) A subcategoria Auditoria Interna apresenta um total de observações de 51 em vez de 115, pois na estrutura organizacional dos órgãos públicos não há a obrigatoriedade da auditoria interna, portanto, para esse item, nos órgãos públicos, se utilizou a nomenclatura não aplicável. (3) RM: relevância média das subcategorias calculada com base na relevância média dos itens de evidenciação, sendo 1 não relevante, 2 pouco relevante, 3 médio relevante, 4 relevante e 5 muito relevante, atribuída pelos analistas da CGU.

A categoria geral apresentou o maior nível de divulgação (65\%), cuja subcategoria mais expressiva foi o histórico da entidade (92\%), por conter itens atinentes à identificação e, portanto, de divulgação quase integral pelas entidades. Merece destaque, nessa categoria, o item divulgação do relatório de gestão (nos sites institucionais), de caráter obrigatório e com um índice médio de 66\% (fundações: $86 \%$; autarquias: 59\% e órgão público: 52\%). Esse item é um nítido indicador da deficiência da transparência no setor público, pois, mesmo obrigatório, ainda assim os níveis de divulgação dos relatórios de gestão anuais atingem pouco mais da metade das organizações públicas federais. 
A categoria financeira mostrou um baixo nível de divulgação (37\%), explicado pela subcateria demonstrações financeiras (9\%). Esse resultado foi oposto ao encontrado em Bakar e Saleh (2011), com um nível de divulgação de 62,6\%. No entanto, esse resultado não indica uma anomalia no setor público brasileiro, uma vez que não é exigida a apresentação das demonstrações financeiras, nos relatórios de gestão anuais, das entidades públicas. Pois as demonstrações financeiras estão disponíveis, para os órgãos de controle, no Sistema de Administração Financeira e Orçamentária (Siafi) do governo federal. Mas, em termos de transparência pública para o cidadão, é uma limitação, que poderia ser parcialmente minimizada pela subcategoria - análise do desempenho orçamentário e financeiro. Todavia, seus resultados apresentaram um baixo nível de transparência (39\%), indicando uma relutância do gestor em divulgar a informação financeira.

Notadamente, a categoria governança revelou o menor nível de divulgação (13\%), explicado pelas subcategorias governança da diretoria e auditoria interna, com uma evidenciação de 4\% e 2\%, respectivamente. Relativo à primeira, a baixa evidenciação é consistente com os achados de Bakar e Saleh (2011) e Ryan, Stanley e Nelson (2002), que apontaram um grau de evidenciação de 3,6\% e 2,7\%, respectivamente. Essa baixa evidenciação decorre, provavelmente, do fato de que os itens da subcategoria governança da diretoria são voluntários e se referem às qualificações e remunerações dos dirigentes.

A categoria desempenho teve uma evidenciação de 44\%, destacando a subcategoria indicadores de desempenho, que, embora obrigatória, obteve somente 59\% de divulgação. Ou seja, as ferramentas projetadas para avaliar as ações governamentais são pouco divulgadas, ou, mais preocupante, não foram implementadas pelas entidades públicas. A subcategoria indicador de satisfação do cliente/empregado atingiu a menor divulgação (18\%) dentro da categoria, mas consistente com Bakar e Saleh (2011) com 13,5\%. E, conforme os autores, vislumbra uma situação desfavorável, uma vez que esse tipo de indicador é visto como muito importante para o setor público.

Adicionalmente, o estudo evidenciou que entre os 112 itens de evidenciação, 10 itens (voluntários), ou seja, $9 \%$ do total ou 17\% do voluntário não são divulgados por nenhuma organização pública federal, como: política de remuneração, remuneração individual dos dirigentes, revisão e avaliação do risco gerencial, independência da função de auditoria e lista dos principais ativos (tamanho). Enquanto apenas sete itens (obrigatórios), ou seja, 6\% do total ou $13 \%$ do obrigatório, foram divulgados por todas as entidades públicas, quais sejam: endereço, telefone, e-mail, site eletrônico, situação funcional, natureza jurídica, estatísticas de recursos humanos e totais da remuneração.

Observa-se que nenhum item voluntário consta como 100\% de divulgação entre as entidades analisadas, mas o inquietante é verificar que, dos 52 itens obrigatórios, apenas sete foram integralmente divulgados, e desses, cinco itens se referem, simplesmente, à identificação da instituição.

Quanto à relevância dos itens de evidenciação, pontuada pelos respondentes, se observa que as categorias Financeira e Desempenho foram classificados entre relevantes e muito relevantes, com destaque para as subcategorias demonstrações financeiras $(4,52)$ e indica- 
dores de desempenho (4,33). Todavia, essas subcategorias apresentaram baixos níveis de divulgação, 9\% e 59\%, respectivamente. Merece destaque a subcategoria demonstrações financeiras, que, embora voluntária, é percebida pelos respondentes como muito relevante na apresentação do relatório de gestão anual. Verifica-se, ainda, que a subcategoria com a maior relevância foi controles internos (4,70), obrigatória, e com um nível de divulgação de 87\%.

As categorias Geral, Governança e Outros foram consideradas de média relevância, sendo a subcategoria governança da diretoria, de menor relevância $(2,83)$. Interessante destacar que essa subcategoria engloba aspectos como: remuneração e qualificação dos dirigentes, mas, na percepção dos respondentes, não são essenciais para apresentação nos relatórios de gestão.

\subsection{Análise das diferenças entre o índice dicotômico e ponderado e das práticas de transparência entre as entidades públicas}

A tabela 4 apresenta o teste de diferenças de médias paramétrico ${ }^{13}$ (teste $t$ pareado) para o índice dicotômico e ponderado (teste da hipótese $\mathrm{H}_{\mathrm{a}}$ ) Os resultados (painel 1 da tabela 3) mostram que a diferença é estatisticamente significativa e permite rejeitar a hipótese nula de igualdade dos índices. Todavia, essa diferença é pequena e consistente com estudos anteriores (Coy e Dixon, 2004; Ryan, Stanley e Nelson, 2002), que sugerem a utilização de ambos os índices para minimizar o problema da subjetividade na ponderação, visto a pouca variabilidade dos resultados.

Tabela 4

Teste de diferenças de médias dos índices de transparência pública federal (ITPF) dicotômico e ponderado para amostra total e estratificada

\begin{tabular}{|c|c|c|c|c|c|}
\hline \multicolumn{6}{|c|}{ Painel 1: Amostra total $(n=115)$} \\
\hline & Índices Pareados & Média & Desvio padrão & Erro padrão & $\mathrm{t}$ \\
\hline Par 1 & DIC versus PON & $-0,011$ & 0,006 & 0,001 & $-19,149 *$ \\
\hline Par 2 & DIC_OBG versus PON_OBG & 0,006 & 0,007 & 0,001 & $9,553^{*}$ \\
\hline Par 3 & DIC_VOL versus PON_VOL & $-0,007$ & 0,010 & 0,001 & $-6,805^{*}$ \\
\hline \multicolumn{6}{|c|}{ Painel 2: Amostra estratificada autarquia $(n=37)$} \\
\hline & Índices Pareados & Média & Desvio padrão & Erro padrão & $\mathrm{t}$ \\
\hline Par 4 & DIC versus PON & $-0,0135$ & 0,0061 & 0,0010 & $-13,365^{*}$ \\
\hline Par 5 & DIC_OBG versus PON_OBG & 0,0033 & 0,0072 & 0,0012 & $2,745^{*}$ \\
\hline Par 6 & DIC_VOL versus PON_VOL & $-0,0083$ & 0,0090 & 0,0015 & $-5,647 *$ \\
\hline
\end{tabular}

\footnotetext{
${ }^{13}$ Foram realizados, também, os testes não paramétricos (teste de Wilcoxon) cujos resultados foram consistentes com os paramétricos.
} 


\begin{tabular}{|c|c|c|c|c|c|}
\hline \multicolumn{6}{|c|}{ Painel 3: Amostra estratificada fundação $(n=14)$} \\
\hline & Índices Pareados & Média & Desvio padrão & Erro padrão & $\mathrm{t}$ \\
\hline Par 7 & DIC & $-0,0101$ & 0,0060 & 0,0016 & $-6,286^{*}$ \\
\hline Par 8 & DIC_OBG versus PON_OBG & 0,0051 & 0,0056 & 0,0015 & $3,401 *$ \\
\hline Par 9 & DIC_VOL versus PON_VOL & $-0,0092$ & 0,0226 & 0,0060 & $-1,529$ \\
\hline \multicolumn{6}{|c|}{ Painel 4: Amostra estratificada órgão público ( $n=64)$} \\
\hline & Índices Pareados & Média & Desvio padrão & Erro padrão & $\mathrm{t}$ \\
\hline Par 10 & Versus PON & $-0,0094$ & 0,0055 & 0,0007 & $-13,540^{*}$ \\
\hline Par 11 & DIC_OBG versus PON_OBG & 0,0077 & 0,0061 & 0,0008 & $10,126^{*}$ \\
\hline Par 12 & DIC_VOL versus PON_VOL & $-0,0050$ & 0,0062 & 0,0008 & $-6,500 *$ \\
\hline
\end{tabular}

Fonte: Elaborada pelos autores (2013).

Nota: (1) DIC: índice dicotômico; PON: índice ponderado; OBR: itens obrigatórios; VOL: itens voluntários. (2) * 1\%, ** 5\% e *** 10\% nível de significância.

Percebe-se, também, que o teste paramétrico da amostra total (painel 1 da tabela 4) revela uma diferença cada vez menor entre os índices dicotômico e ponderado (total, obrigatório e voluntário), conforme indica o coeficiente t de student. Assim, observa-se que as menores diferenças de médias encontram-se nos índices voluntários, possivelmente, devido ao reduzido quantitativo de itens divulgados e sem muita variabilidade entre as entidades públicas federais.

Apesar de os testes estatísticos confirmarem as diferenças de médias entre os índices dicotômico e ponderado, se constata que a pequena diferença (em termos percentuais), decorrente da atribuição de relevância aos itens de evidenciação, não afeta de forma significativa a mensuração do índice de transparência pública federal total.

A tabela 5 apresenta o resultado do teste paramétrico ${ }^{14}$ de diferenças de médias para amostras independentes (teste da hipótese $\mathrm{H}_{\mathrm{b}}$ ) para os índices de transparência entre as entidades públicas. Os resultados (painel 1 da tabela 4) revelam que não há diferenças significativas nas práticas de evidenciação na administração pública indireta (autarquias e fundações). Mas relativamente às autarquias e aos órgãos públicos (painel 2 da tabela 5), e às fundações e aos órgãos públicos (painel 3 da tabela 5), a hipótese nula foi rejeitada, ou seja, existem diferenças estatisticamente significativas nas práticas de evidenciação entre esses grupos.

\footnotetext{
${ }^{14}$ Foram realizados, também, os testes não paramétricos (teste de Mann-Whitney), cujos resultados se mostram consistentes com os paramétricos.
} 
Tabela 5

\section{Teste de diferenças de médias do Índice de Transparência Pública Federal (ITPF) entre as entidades}

\begin{tabular}{|c|c|c|c|c|c|c|c|c|}
\hline \multicolumn{9}{|c|}{ Painel 1: Teste $t$ de amostras independentes entre autarquia $(n=37)$ e fundação $(n=14)$} \\
\hline \multicolumn{2}{|c|}{ Índices de Transparência } & \multicolumn{2}{|c|}{$\begin{array}{l}\text { Teste de Levene } \\
\text { para igualdade de } \\
\text { variações }\end{array}$} & \multicolumn{5}{|c|}{ Teste t para Igualdade de Médias } \\
\hline & Variâncias assumidas & $\mathrm{F}$ & Sig. & $\mathrm{t}$ & $\mathrm{df}$ & Sig* & Dif. média & Erro padrão \\
\hline \multirow[t]{2}{*}{ DIC } & Iguais & 1,538 & 0,221 & $-0,397$ & 49 & 0,693 & $-0,009$ & 0,023 \\
\hline & Diferentes & & & $-0,435$ & 28,589 & 0,667 & $-0,009$ & 0,021 \\
\hline \multirow[t]{2}{*}{ PON } & Iguais & 1,537 & 0,221 & $-0,242$ & 49 & 0,810 & $-0,006$ & 0,025 \\
\hline & Diferentes & & & $-0,263$ & 27,904 & 0,795 & $-0,006$ & 0,023 \\
\hline \multirow[t]{2}{*}{ DIC_OBG } & Iguais & 2,083 & 0,155 & $-1,037$ & 49 & 0,305 & $-0,023$ & 0,022 \\
\hline & Diferentes & & & $-1,170$ & 30,637 & 0,251 & $-0,023$ & 0,019 \\
\hline \multirow[t]{2}{*}{ DIC_VOL } & Iguais & 0,247 & 0,621 & 0,100 & 49 & 0,921 & 0,003 & 0,030 \\
\hline & Diferentes & & & 0,109 & 27,993 & 0,914 & 0,003 & 0,028 \\
\hline \multirow[t]{2}{*}{ PON_OBG } & Iguais & 1,969 & 0,167 & $-0,904$ & 49 & 0,371 & $-0,021$ & 0,023 \\
\hline & Diferentes & & & $-1,015$ & 30,252 & 0,318 & $-0,021$ & 0,020 \\
\hline \multirow[t]{2}{*}{ PON_VOL } & Iguais & 0,004 & 0,951 & 0,064 & 49 & 0,949 & 0,002 & 0,033 \\
\hline & Diferentes & & & 0,065 & 24,175 & 0,949 & 0,002 & 0,032 \\
\hline \multicolumn{9}{|c|}{ Painel 2: Teste $t$ de amostras independentes entre autarquia $(n=37)$ e órgão público $(n=64)$} \\
\hline \multicolumn{2}{|c|}{ Índices de Transparência } & $\begin{array}{r}\text { Teste de } \\
\text { para igu } \\
\text { varia }\end{array}$ & $\begin{array}{l}\text { vene } \\
\text { ide e } \\
\text { s }\end{array}$ & \multicolumn{5}{|c|}{ Teste t para Igualdade de Médias } \\
\hline & Variâncias assumidas & $\mathrm{F}$ & Sig. & $\mathrm{t}$ & $\mathrm{df}$ & Sig* & Dif. média & Erro padrão \\
\hline \multirow[t]{2}{*}{ DIC } & Iguais & 0,345 & 0,558 & 5,150 & 99 & 0,000 & 0,080 & 0,016 \\
\hline & Diferentes & & & 5,064 & 71,498 & 0,000 & 0,080 & 0,016 \\
\hline \multirow[t]{2}{*}{ PON } & Iguais & 0,305 & 0,582 & 5,160 & 99 & 0,000 & 0,084 & 0,016 \\
\hline & Diferentes & & & 5,085 & 72,003 & 0,000 & 0,084 & 0,017 \\
\hline \multirow[t]{2}{*}{ DIC OBG } & Iguais & 4,320 & 0,040 & 6,206 & 99 & 0,000 & 0,123 & 0,020 \\
\hline & Diferentes & & & 6,832 & 95,809 & 0,000 & 0,123 & 0,018 \\
\hline \multirow[t]{2}{*}{ DIC VOL } & Iguais & 6,517 & 0,012 & 4,155 & 99 & 0,000 & 0,068 & 0,016 \\
\hline & Diferentes & & & 3,707 & 53,314 & 0,001 & 0,068 & 0,018 \\
\hline \multirow[t]{2}{*}{ PON OBG } & Iguais & 3,856 & 0,052 & 6,247 & 99 & 0,000 & 0,128 & 0,020 \\
\hline & Diferentes & & & 6,831 & 94,763 & 0,000 & 0,128 & 0,019 \\
\hline \multirow[t]{2}{*}{ PON VOL } & Iguais & 6,298 & 0,014 & 4,146 & 99 & 0,000 & 0,071 & 0,017 \\
\hline & Diferentes & & & 3,700 & 53,348 & 0,001 & 0,071 & 0,019 \\
\hline
\end{tabular}

Continua 


\begin{tabular}{|c|c|c|c|c|c|c|c|c|}
\hline \multicolumn{9}{|c|}{ Painel 3: Teste $t$ de amostras independentes entre fundação $(n=14)$ e órgão público $(n=64)$} \\
\hline \multicolumn{2}{|c|}{ Índices de Transparência } & \multicolumn{2}{|c|}{$\begin{array}{c}\text { Teste de Levene } \\
\text { para igualdade de } \\
\text { variações }\end{array}$} & \multicolumn{5}{|c|}{ Teste t para Igualdade de Médias } \\
\hline & Variâncias assumidas & $\mathrm{F}$ & Sig. & $\mathrm{t}$ & df & Sig* & Dif. média & Erro padrão \\
\hline \multirow[t]{2}{*}{ DIC } & Iguais & 0,805 & 0,373 & 4,208 & 76 & 0,000 & 0,090 & 0,021 \\
\hline & Diferentes & & & 4,606 & 21,242 & 0,000 & 0,090 & 0,019 \\
\hline \multirow[t]{2}{*}{ PON } & Iguais & 0,843 & 0,362 & 4,022 & 76 & 0,000 & 0,090 & 0,022 \\
\hline & Diferentes & & & 4,360 & 20,979 & 0,000 & 0,090 & 0,021 \\
\hline \multirow[t]{2}{*}{ DIC OBG } & Iguais & 5,553 & 0,021 & 4,940 & 76 & 0,000 & 0,146 & 0,029 \\
\hline & Diferentes & & & 7,244 & 36,792 & 0,000 & 0,146 & 0,020 \\
\hline \multirow[t]{2}{*}{ DIC VOL } & Iguais & 1,959 & 0,166 & 3,244 & 76 & 0,002 & 0,065 & 0,020 \\
\hline & Diferentes & & & 2,734 & 16,497 & 0,014 & 0,065 & 0,024 \\
\hline \multirow[t]{2}{*}{ PON OBG } & Iguais & 5,247 & 0,025 & 4,905 & 76 & 0,000 & 0,149 & 0,030 \\
\hline & Diferentes & & & 7,045 & 34,921 & 0,000 & 0,149 & 0,021 \\
\hline \multirow[t]{2}{*}{ PON VOL } & Iguais & 3,664 & 0,059 & 3,147 & 76 & 0,002 & 0,069 & 0,022 \\
\hline & Diferentes & & & 2,423 & 15,569 & 0,028 & 0,069 & 0,029 \\
\hline
\end{tabular}

Fonte: Elaborada pelos autores (2013).

Notas: (1) DIC: índice dicotômico; PON: índice ponderado; OBR: itens obrigatórios; VOL: itens voluntários; (2) * significância (2 extremidades).

Do exposto, verifica-se que os testes estatísticos confirmaram os resultados apurados na análise preliminar do ITPF total, ou seja, existem práticas de evidenciação distintas entre a administração pública direta federal (órgãos públicos) e a indireta federal (autarquias e fundações).

\subsection{Análise multivariada dos incentivos e variáveis associados ao nível de transparência pública dos entes governamentais federais}

A tabela 6 mostra os resultados dos modelos de regressão da análise dos incentivos em relação às práticas de transparência pública das entidades federais (teste da hipótese $\mathrm{H}_{\mathrm{c}}$ ). ${ }^{15}$ É possível observar que todos os modelos são estatisticamente significantes ( $p>0,001$ ), com rejeição da hipótese nula, isto é, pelo menos uma das variáveis independentes testadas apresenta relação com a transparência pública federal. ${ }^{16} \mathrm{O}$ poder explicativo ( $\mathrm{R}^{2}$ ajustado) se apresentou rela-

\footnotetext{
${ }^{15}$ Somente um par de variáveis independentes, tipo da entidade (Tipo) e auditoria interna (Audit) apresentou alta correlação de 0,844 (>0,70) e, portanto, não foi considerado no modelo.

${ }^{16}$ Os testes das premissas estatísticas foram conduzidos para evitar a multicolinearidade, autocorrelação e heterocedasticidade entre as variáveis nos modelos de regressão. Para determinar se a multicolinearidade afetava os resultados
} 
tivamente baixo para todos os modelos, sendo o índice dicotômico obrigatório $(0,455)$ com o maior poder explicativo, enquanto o índice ponderado voluntário apresentou o menor $\mathrm{R}^{2}$ $(0,177)$. Destaca-se que esses resultados são consistentes com os coeficientes de variação $\left(\mathrm{R}^{2}\right)$ encontrados em estudos anteriores: 0,35 em Ingram (1984); 0,24 a 0,13 em Giroux (1989); 0,23 a 0,21 em Laswad, Fisher e Oleyere (2005) e 0,32 em Bakar e Saleh (2011).

Os modelos 3 e 4 (índice de transparência obrigatório dicotômico e ponderado) apresentaram o maior poder explicativo (45\%), possivelmente em face dos melhores níveis de divulgação (80\%), visto a exigência legal. Enquanto os modelos 5 e 6 (índice de transparência voluntário dicotômico e ponderado) apresentaram o menor $\mathrm{R}^{2}(17 \%)$, que pode ser explicado pelo baixo nível de evidenciação da informação complementar (19\%) nos relatórios de gestão anuais.

As variáveis estatisticamente significantes nos modelos de regressão completos (modelos 1 e 2) foram: (a) demografia de pessoal (+), (b) acessibilidade $(+)$, (c) tipo da entidade $(+)$ e $(d)$ burocracia pública $(-)$. No presente estudo, a variável demografia de pessoal (Demo), representativa do incentivo institucional, mostrou uma relação positiva (modelos 1 e 2) com o nível de transparência pública total ( $p>0,10)$, análogo a Ingram (1984) e Cheng (1992), que apontam que o profissionalismo público (treinamento, salários, expertise técnica e formação educacional) influencia de forma positiva a extensão e a qualidade da divulgação da informação no setor público. Adicionalmente, o índice de transparência voluntário (modelos 5 e 6) apresentou relação positiva com a variável. Esse resultado pode significar que as entidades públicas com maiores custos de pessoal, por funcionário, tendem a ser mais transparentes nas práticas de evidenciação voluntárias de forma a justificar e legitimar sua necessidade perante a sociedade.

Concernente à variável acessibilidade (Acess), representativa do incentivo social, também apresentou uma relação positiva e significativa com as práticas de transparência pública e consistente com a literatura prévia (Zimmerman, 1977; Bakar e Saleh, 2011). Isto é, quanto mais acessível a informação pública à sociedade, reflete um maior comprometimento com a transparência e a responsabilização pública.

A variável tipo da entidade (Tipo), representativa do incentivo governamental, foi a única que mostrou relação positiva em todos os modelos de regressão com o ITPF, demonstrando que as entidades públicas da administração indireta federal (autarquias e fundações) são mais transparentes que as entidades da administração direta federal (órgãos públicos). Percebe-se que, quanto mais próximo do núcleo do poder, menos transparente (conflito de agência), confirmando a análise univariada e aderente com Laswad, Fisher e Oleyere (2005), que apontam que o tipo governamental está positivamente associado a variações nos níveis de transparência no setor público, pois uma administração mais gerencial tende a ser mais transparente.

da regressão, foi calculado o VIF (variation inflation factor) para todas as variáveis independentes, sendo o maior VIF encontrado de 1,77. Também não foram encontradas evidências de heterocesdasticidade entre as variáveis, e os testes de autocorrelação, como demonstrado na tabela 5 , não evidenciaram problemas. 
Tabela 6

Resultado dos testes dos modelos de regressão linear ( $n=115$ entes públicos)

\begin{tabular}{|c|c|c|c|c|c|c|c|}
\hline \multicolumn{8}{|c|}{$\mathrm{Y}_{\mathrm{i}}=\beta_{0}+\beta_{1} \mathrm{PORTE}_{\mathrm{i}}+\beta_{2} \mathrm{DEMO}_{\mathrm{i}}-\beta_{3}$ TAM_NG $_{\mathrm{i}}+\beta_{4} \mathrm{TIPO}_{\mathrm{i}}+\beta_{5} \mathrm{BP}_{\mathrm{i}}+\beta_{6}$ ACESS $_{\mathrm{i}}+\beta_{7}$ REC_ORC $_{\mathrm{i}}+\beta_{8}$ DEP_FED $_{\mathrm{i}}+\mu_{\mathrm{i}}$} \\
\hline \multicolumn{2}{|l|}{ Variável dependente: } & ITPF_DIC & ITPF_PON & $\begin{array}{l}\text { ITPF }_{-} \\
\text {DICOBR }\end{array}$ & $\begin{array}{c}\text { ITPF }_{-} \\
\text {PONOBR }\end{array}$ & $\begin{array}{l}\text { ITPF }_{-} \\
\text {DICVOL }\end{array}$ & $\begin{array}{l}\text { ITPF } \\
\text { PONVOL }\end{array}$ \\
\hline Incentivos & $\begin{array}{c}\text { Variáveis } \\
\text { independentes } \\
\text { (sinal esperado) }\end{array}$ & $\begin{array}{c}\text { Modelo } \\
1\end{array}$ & $\begin{array}{c}\text { Modelo } \\
2\end{array}$ & $\begin{array}{c}\text { Modelo } \\
3\end{array}$ & $\begin{array}{c}\text { Modelo } \\
4\end{array}$ & $\begin{array}{l}\text { Modelo } \\
5\end{array}$ & $\begin{array}{c}\text { Modelo } \\
6\end{array}$ \\
\hline \multirow{3}{*}{ POLÍTICO } & Constante & $(11,175)^{*}$ & $(10,903)^{*}$ & $(15,746)^{*}$ & $(15,184)^{*}$ & $(2,705)^{*}$ & $(2,545)^{*}$ \\
\hline & PORTE $(+)$ & 0,106 & 0,098 & 0,109 & 0,091 & 0,116 & 0,119 \\
\hline & & $(1,047)$ & $(0,965)$ & $(1,184)$ & $(0,989)$ & $(1,028)$ & $(1,049)$ \\
\hline \multirow[t]{4}{*}{ INSTITUCIONAL } & DEMO (-) & $0,130 * * *$ & $0,130 * * *$ & 0,074 & 0,073 & $0,167^{* * *}$ & $0,174 * *$ \\
\hline & & $(1,672)$ & $(1,675)$ & $(1,051)$ & $(1,029)$ & $(1,920)$ & $(2,001)$ \\
\hline & TAM_NG (-) & $-0,022$ & $-0,021$ & $-0,032$ & $-0,028$ & $-0,018$ & $-0,021$ \\
\hline & & $(-0,249)$ & $(-0,246)$ & $(-0,400)$ & $(-0,357)$ & $(-0,162)$ & $(-0,216)$ \\
\hline \multirow[t]{2}{*}{ SOCIAL } & ACESS (+) & $0,161^{* *}$ & $0,168 * *$ & $0,183^{*}$ & $0,191^{*}$ & 0,086 & 0,089 \\
\hline & & $(2,058)$ & $(2,139)$ & $(2,561)$ & $(2,671)$ & $(0,986)$ & $(1,015)$ \\
\hline \multirow[t]{4}{*}{ FINANCEIRO } & REC_ORC (+) & 0,113 & 0,118 & 0,100 & 0,103 & 0,083 & 0,085 \\
\hline & & $(1,397)$ & $(1,458)$ & $(1,352)$ & $(1,400)$ & $(0,911)$ & $(0,943)$ \\
\hline & DEP_FED (+) & $-0,028$ & $-0,032$ & 0,016 & 0,016 & $-0,054$ & $-0,065$ \\
\hline & & $(-0,346)$ & $(-0,403)$ & $(0,218)$ & $(0,219)$ & $(-0,605)$ & $(-0,726)$ \\
\hline \multirow[t]{5}{*}{ GOVERNAMENTAL } & TIPO (+) & $0,381^{*}$ & $0,381^{*}$ & $0,449 *$ & $0,455^{*}$ & $0,317^{*}$ & $0,314 *$ \\
\hline & & $(4,065)$ & $(4,059)$ & $(5,258)$ & $(5,322)$ & $(3,024)$ & $(2,997)$ \\
\hline & BP $(-)$ & $-0,207^{* *}$ & $-0,207^{* *}$ & $-0,245^{*}$ & $-0,244^{*}$ & $-0,083$ & $-0,77$ \\
\hline & & $(-2,422)$ & $(-2,419)$ & $(-3,141)$ & $(-3,130)$ & $(-0,868)$ & $(-0,806)$ \\
\hline & $\mathrm{R}^{2}$ Ajustado & 0,344 & 0,342 & 0,455 & 0,453 & 0,178 & 0,177 \\
\hline \multirow{3}{*}{$\begin{array}{l}\text { Parâmetros dos } \\
\text { modelos }\end{array}$} & Durbin-Watson & 1,587 & 1,584 & 1,907 & 1,909 & 1,452 & 1,459 \\
\hline & F-estatístico & 8,474 & 8,399 & 12,900 & 12,262 & 4,468 & 4,463 \\
\hline & Sig & 0,000 & 0.000 & 0.000 & 0.000 & 0.000 & 0.000 \\
\hline
\end{tabular}

Fonte: Elaborada pelos autores (2013).

Nota: (1) A tabela apresenta o coeficiente beta padronizado. (2) Os valores entre parênteses se referem à estatística t. (3) As variáveis dummy são Tipo e Acess. (4) Os entes classificados no grupo "1" correspondem: (a) Acess: entes que divulgam o relatório de gestão no site e (b) Tipo: entes que pertencem à administração pública indireta. (5) *1\%, **5\%, ***10\% nível de significância. (6) DIC: índice dicotômico; PON: índice ponderado; OBR: itens obrigatórios; VOL: itens voluntários.

Por fim, a burocracia pública (BP), representativa do incentivo governamental, relaciona-se com os índices de transparência pública total (modelos 1 e 2) e obrigatório (modelos 3 e 4). Contudo, de forma negativa, isto é, quanto maior o percentual dos cargos comissionados na entidade pública, menor o nível de evidenciação nos relatórios de gestão anuais. 
Esse resultado é similar ao estudo de Giroux (1989), que argumenta que a burocracia pública possui reduzido incentivo em divulgar informação, vista a possibilidade de comprometer seus cargos (conflito de agência), e, dessa forma, prefere práticas de evidenciação que ofereçam um limitado monitoramento das ações governamentais.

Quanto a porte, receita orçamentária, tamanho do núcleo de gestão e dependência federal, nenhum modelo se relaciona com o índice de transparência pública. Relativo ao resultado das duas últimas variáveis, ele é semelhante a Bakar e Saleh (2011), que argumentam: (i) as transferências de recursos federais seriam automáticas e, portanto, não estariam condicionadas a melhores práticas de divulgação. A argumentação cabe, perfeitamente, no cenário público brasileiro, uma vez que as transferências federais estão atreladas à disponibilidade orçamentária, não considerando o desempenho da entidade. E o tamanho do núcleo de gestão (maior ou menor) também não afeta os níveis de divulgação da informação pública, nos relatórios de gestão anuais, das entidades federais. Adicionalmente, o fato de o porte da entidade governamental não estar relacionado à transparência pública mostrou-se contrário à literatura majoritária. Todavia, consistente com o estudo de Laswad, Oleyere e Fisher (2005), cujo resultado foi não significativo, ou seja, o tamanho da entidade não é fator preditivo para melhores níveis de transparência pública.

Os achados também evidenciam que o incentivo governamental (tipo da entidade) é o determinante que melhor explica as práticas de evidenciação no setor público. Entretanto, esforços devem ser canalizados no âmbito do setor público brasileiro para permitir maior acessibilidade aos relatórios de gestão anuais, pois, como fundamentado no referencial teórico, eles contribuem para melhores práticas de transparência e maior responsabilização dos gestores públicos.

Em resumo, os resultados podem indicar ainda a existência de assimetria informacional entre o gestor público e os cidadãos, visto que os níveis de transparência pública federal apresentados nos relatórios de gestão anuais ainda são relativamente baixos, principalmente, quando considerada a evidenciação voluntária. Portanto, o desenvolvimento de ferramentas de disponibilização da informação pública, seja via relatórios de gestão anuais (prestação de contas formais), relatórios fiscais (LRF), portais de transparência (controle social) ou solicitações ativas (LAI), promove uma melhoria nos níveis de aproximação entre gestor público e sociedade.

\section{Considerações finais}

Este estudo objetivou analisar o nível de transparência pública apresentado nos relatórios de gestão anuais das entidades públicas federais e os incentivos políticos, sociais, institucionais, financeiros e governamentais que contribuem para a maior ou menor transparência. Para alcançar o objetivo, foi construído um índice de transparência pública federal baseado em relatórios de gestão anuais e, em linhas gerais, os dados demonstraram que:

a) O índice médio total de transparência pública federal é de, aproximadamente, 48\%, revelando, de um modo geral, que a transparência ainda é baixa; 
b) Existem evidências estatísticas de que os índices de transparência pública (ITPF total) dicotômico e ponderado são diferentes. Apesar de as diferenças serem pequenas, em termos percentuais, os resultados estatísticos corroboraram a importância da ponderação do índice de transparência indicando que os itens de evidenciação possuem grau de importância distinto para os usuários;

c) Existem evidências estatísticas de que o nível de transparência pública entre a administração direta federal (órgãos públicos) e a administração indireta federal (autarquias e fundações) é diferente, isto é, os últimos mostram melhores práticas de evidenciação da informação pública nos relatórios de gestão anuais (54\% — autarquias e 55\% — fundações contra 46\% - órgãos públicos). Assim, verifica-se que o tipo de entidade (indireta ou direta) afeta as práticas de divulgação nos relatórios de gestão anuais federais;

d) O nível médio de evidenciação obrigatória (80\%) apresentado nos relatórios de gestão ainda é baixo, visto que todos os itens deveriam ser integralmente divulgados. Ressalta-se que apenas uma entidade pública federal (fundação) apresentou 100\% dos itens obrigatórios, enquanto uma entidade (órgão público) divulgou apenas 45\% dos itens;

e) O nível médio de transparência voluntário é extremamente baixo (19\%), demonstrando que ainda é possível melhorar bastante a divulgação das informações por parte dos gestores governamentais;

f) A demografia de pessoal, acessibilidade, tipo de entidade e burocracia pública apresentou relação positiva (as três primeiras) e negativa (a última) com o nível de transparência pública federal. Por outro lado, as variáveis: porte, tamanho do núcleo de gestão, receita orçamentária e dependência federal não afetam o índice;

g) As categorias financeira e desempenho, representantes da condução financeira e física da gestão pública, obtiveram baixos índices de divulgação, 37\% e 44\%, respectivamente;

h) A percepção dos respondentes mostrou que as subcategorias demonstrações financeiras e indicadores de desempenho foram consideradas de maior relevância, embora com baixos índices de evidenciação nos relatórios de gestão anuais analisados. Enquanto a subcategoria que apresentou os melhores índices de divulgação (histórico do órgão) foi considerada pouco relevante pelos respondentes;

i) Nenhuma entidade pública federal divulgou todos os itens de evidenciação, sendo o ITPF total máximo de 74\% (autarquias).

No estudo, surpreende bastante o fato de apenas uma entidade pública divulgar todos os itens obrigatórios entre as 115 analisadas. Essa situação espelha uma deficiência no processo de responsabilização (accountability) e que as entidades públicas federais ainda se encontram distantes de uma divulgação transparente nos relatórios de gestão anuais.

O índice de transparência voluntário revelou uma aderência expressivamente baixa (19\%) das entidades analisadas. E, segundo Laswad, Fisher e Oleyere (2005), evidencia que 
as práticas de evidenciação voluntária ainda estão num estágio de desenvolvimento no setor público e, portanto, requerem uma maior reflexão pelos gestores públicos.

Pode-se concluir que, apesar da existência, na esfera pública federal, de uma regulamentação concernente às práticas de divulgação obrigatória, elas ainda não são integralmente atendidas.

Nessa linha, a contribuição prática do estudo é: (a) apresentar o atual estágio, antes das International Public Sector Accounting Standards (Ipsas), das práticas de transparência pública nos relatórios de gestão anuais das entidades públicas federais; (b) demonstrar oportunidades de melhorias na evidenciação da informação pública nos relatórios de gestão; e (c) destacar a necessidade do integral atendimento às práticas de evidenciação obrigatórias, condição para uma apropriada prestação de contas (accountability) dos gestores.

No campo acadêmico se confirmou a importância dos incentivos institucional, governamental e social como motivadores para melhores índices de transparência pública, mas também foram apresentadas evidências empíricas, no contexto brasileiro, de características peculiares quanto à prestação de contas e à elaboração dos relatórios de gestão. Ressalta-se, ainda, o reduzido número de estudos, no setor público brasileiro, e, nesse sentido, a contribuição para reflexão acadêmica sob a ótica da análise da transparência pública federal nos relatórios de gestão anuais e, mais especificamente, pelos incentivos que motivam ou não a evidenciação das informações públicas federais.

As principais limitações do estudo são expostas a seguir: (i) abordagem de corte transversal (relatórios de gestão anuais de 2010), portanto, um estudo longitudinal poderia captar melhor as mudanças nas práticas de divulgação no decorrer dos períodos. Além disso, a convergência com as Ipsas no setor público brasileiro pode alterar significativamente os resultados em exercícios subsequentes; (ii) subjetividade inerente à construção de índices de evidenciação, na quantificação e identificação das informações constantes dos relatórios de gestão; (iii) análise de conteúdo em um único instrumento de divulgação (relatórios de gestão); (iv) pontuação da relevância considerou apenas um nicho de respondentes, e nesse quesito pode conter algum viés; (v) limitação das proxies (variáveis) empregadas para representar os incentivos analisados ou ausência de variáveis relevantes; (vi) os resultados não podem ser generalizados para todo o setor público brasileiro; e (vii) possíveis erros na coleta dos dados das variáveis, utilizadas nos testes estatísticos, e na mensuração do índice.

Para futuras pesquisas podem ser apontadas as seguintes questões: (i) ampliar a amostra para outras entidades públicas e esferas governamentais; (ii) mensurar a transparência pública após a convergência com as Ipsas; (iii) utilizar outro público para graduar a relevância; (iv) aumentar o número de variáveis analisadas, como variáveis de desempenho.

\section{Referências}

ALBUQUERQUE, João H. M. et al. Um estudo sob a óptica da teoria do agenciamento sobre a accountability e a relação Estado-sociedade. In: CONGRESSO USP DE CONTROLADORIA E CONTABILIDADE, 7., 2007, São Paulo. Anais... São Paulo: USP, 2007. p. 26-39. 
BAKAR, Nur B. A.; SALEH, Zakiah. Disclosure of accountability information in public sector: the case of Malaysian federal statutory bodies. In: BIENNIAL CIGAR CONFERENCE: Bridging public sector and non-profit sector accounting, 13., Ghent, June 2011.

BAKAR, Nur B. A.; SALEH, Zakiah. Incentives for disclosure of accounting information in public sector: a literature survey. International Research Journal of Finance and Economics, v. 75, n. 1, p. 24-38, 2011.

BRASIL. Lei Complementar Federal no 101, de 4 de maio de 2000. Estabelece normas de finanças públicas voltadas para a responsabilidade fiscal e dá outras providências. Disponível em: <www. planalto.gov.br/CCIVIL/Leis/LCP/Lcp101.htm>. Acesso em: 14 jun. 2012.

BRASIL. Lei $n^{\circ}$ 12.527, de 18 de novembro de 2011. Regula o acesso à informação previsto no inciso

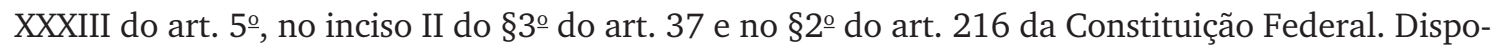
nível em: <www.acessoainformação.gov.br>. Acesso em: 14 jun. 2012.

CHENG, Rita H. An empirical analysis of theories on factors influencing state government accounting disclosure. Journal of Accounting and Public Policy, Maryland, v. 11, n. 1, p. 1-42, 1992.

COPLEY, Paul A. The association between municipal disclosure practices and audit quality. Journal of Accounting and Public Policy, Maryland, v. 10, n. 4, p. 245-266, 1991.

COY, David; DIXON, Keith. The public accountability index: crafting a parametric disclosure index for annual reports. British Accounting Review, v. 36, n. 1, p. 79-106, 2004.

CRUZ, Cláudia F. Transparência da gestão pública municipal: referenciais teóricos e a situação dos grandes municípios brasileiros. Dissertação (mestrado em ciências contábeis) — Programa de Pós-Graduação em Ciências Contábeis, Faculdade de Administração e Ciências Contábeis, Universidade Federal do Rio de Janeiro, Rio de Janeiro, 2010.

GANDIA, Juan L.; ARCHIDONA, Maria C. Determinants of web' site information by Spanish city councils. Online Information Review, v. 32, n. 1, p. 35-57, 2008.

GIROUX, Gary. Political interests and governmental accounting disclosure. Journal of Accounting and Public Policy, v. 8, n. 3, p. 35-57, 1989.

HENDRIKSEN, Eldon S.; VAN BREDA, Michael F. Teoria da contabilidade. 5. ed. São Paulo: Atlas. 1999.

HERAWATY, Merry; HOQUE, Zahirul. Disclosure in the annual reports of Australian government departments: a research note. Journal of Accounting and Organizational Change, v. 3 n. 2, p. 147168, 2007.

IBGC. Instituto Brasileiro de Governança Corporativa. Código das melhores práticas de governança corporativa. 5. ed. São Paulo, 2010. Disponível em: <www.ibgc.org.br/CodigoMelhoresPraticas. aspx>. Acesso em: 15 mar. 2012.

INGRAM, Robert W. Economic incentives and the choice of the sate government accounting practice. Journal of Accounting Research, v. 22, n. 1, p. 126-134, 1984. 
ISHIKURA, Edison R. et al. Proposta de um modelo de relatório para o setor público baseado no Parecer de Orientação ํo 15/87 da Comissão de Valores Mobiliários: um instrumento de governança corporativa para a administração pública. Rev. Adm. Pública, Rio de Janeiro, v. 44, n. 1, p. 42-119, 2010.

JENSEN, Michael C.; MECKLING, William H. Theory of the firm - managerial behavior, agency costs and ownership structure. Journal of Financial Economics, v. 3, n. 4, p. 305-360, out.1976. Disponível em: <www.sfu.ca/ wainwrig/Econ400/jensen-meckling.pdf>. Acesso em: 23 jun. 2011.

KIM, Pan S. et al. Toward participatory and transparent governance: report on the Sixth Global Forum on Reinventing Government. Public Administration Review, v. 65, n. 6, p. 646-654, 2005.

LASWAD, Fawzi; FISHER, Richard; OLEYERE, Peter. Determinants of voluntary internet financial reporting by local government authorities. Journal Accounting and Public Policy, v. 24, n. 2, p. 101121, 2005.

LIM, Stephen; MCKINNON, Jill. Voluntary disclosure by NSW statutory authorities: the influence of political visibility. Journal of Accounting and Public Policy, Maryland, v. 12, n. 1, p. 189-217, 1993.

LOCK, Fernando N. Transparência da gestão municipal através das informações contábeis divulgadas na internet. Dissertação (mestrado em gestão pública para o desenvolvimento do Nordeste) — Universidade Federal de Pernambuco, Recife, 2003.

MAINGOT, Michael; ZEGHAL, Daniel. An analysis of voluntary disclosure of performance indicators by Canadian universities. Tertiary Education and Management, v. 14, n. 4, p. 269-283, 2008.

MARCUCCIO, Manila; STECCOLINI, Ileana. Patterns of voluntary extended performance reporting in Italian local authorities. International Journal of Public Sector Management, Nottingham, v. 22, n. 2, p. 146-167, 2008.

MARTANI, Dwi; LESTIANI, Annisa. Disclosure in local government financial statements: the case of Indonesia. Global Review of Accounting and Finance, v. 3, n. 1, p. 67-84, 2012.

PAIVA, Clarice P. R.; ZUCCOLOTTO, Robson. Índice de transparência fiscal das contas públicas dos municípios obtidas em meios eletrônicos de acesso público. In: ENCONTRO DA ANPAD, XXXIII, 2009, São Paulo. Anais... São Paulo, 2009. 1 CD-ROM.

PEREZ, Carmen C.; BOLIVAR, Manuel P. R.; HERNANDEZ, Antonio M. L. E-Government process and incentives for online public financial information. Online Information Review, v. 32, n. 3, p. 379-400, 2008.

RYAN, Christine M.; STANLEY, Trevor A.; NELSON, Morton. Accountability disclosure by Queensland local government councils: 1997-1999. Financial Accountability and Management, v. 18, n. 3, p. 261-289, 2002.

SACRAMENTO, Ana R. S.; PINHO, José A. G. Transparência na administração pública: o que mudou depois da Lei de Responsabilidade Fiscal? Um estudo exploratório em seis municípios da região metropolitana de Salvador. Revista de Contabilidade da UFBA, Salvador, v. 1, n. 1, p. 48-61, 2007. 
SANTANA JUNIOR, Jorge J. B. Transparência fiscal eletrônica: uma análise dos níveis de transparência apresentados nos sites dos poderes e órgãos dos estados e do Distrito Federal do Brasil. Dissertação (mestrado em ciências contábeis) — Programa Multinstitucional e Inter-regional de Pós-graduação em Ciências Contábeis, Recife, 2008.

SLOMSKI, Valmor. Controladoria e governança na gestão pública. São Paulo: Atlas, 2007.

SLOMSKI, Valmor et al. Transparência fiscal eletrônica: uma análise dos níveis de transparência apresentados nos sites dos poderes e órgãos dos estados e do Distrito Federal do Brasil. Revista de Educação e Pesquisa em Contabilidade, Brasília, v. 3, n. 3, p. 62-84, set./dez. 2009.

SMITH, Kenneth A. Voluntarily reporting performance measures to the public: a test of accounting reports from U.S. cities. International Public Management Journal, v. 7, n. 1, p. 19-48, 2004.

STECCOLINI, Ileana. Local government annual report: an accountability medium? In: Working Paper Series, SDA Bocconi, n. 81, 2002.

TOLENTINO, Marlúcia A. et al. Lei de responsabilidade fiscal: dificuldades e benefícios da implementação e operacionalização na microrregião de Bocaiúva. Unimontes Científica, Montes Claros, v. 3, n. 3, p. 38-55, jun. 2002.

TOOLEY, Stuart; HOOKS, Jillian; BASNAN, Norida. Performance reporting by Malaysian local authorities: identifying stakeholders needs. Financial Accountability and Management, v. 26, n. 2, p. 103-133, 2010.

WEI, Ting L.; DAVEY, Howard; COY, David. A disclosure index to measure the quality of annual reporting by museums in New Zealand and the UK. Journal of Applied Accounting Research, v. 9, n. 1, p. 29-51, 2008.

ZIMMERMAN, Jerold L. The municipal accounting maze: an analysis of political incentives. Journal of Accounting Research, v. 15, p. 107-144, 1977.

Maria Amália da Costa Bairral é mestre em ciências contábeis pela Universidade do Estado do Rio de Janeiro (Uerj) e analista de Finanças e Controle da Controladoria Geral da União (CGU). E-mail: amaliabairral@bol.com.br.

Adolfo Henrique Coutinho e Silva é doutor em contabilidade e controladoria pela Universidade de São Paulo (USP) e professor adjunto da Universidade Federal do Rio de Janeiro (UFRJ). E-mail: adolfocoutinho@uol.com.br.

Francisco Jóse dos Santos Alves é doutor em contabilidade e controladoria pela Universidade de São Paulo (USP) e professor adjunto da Universidade do Estado do Rio de Janeiro (Uerj). E-mail: francisco. jose.alves@terra.com.br. 